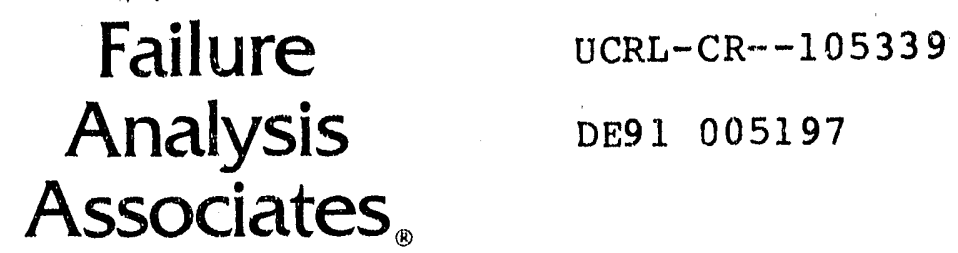

FaAA-SF-R-90-06-06

Engineering and Sclentific Services

149 Commonwealth Drive. P.0.80x 3015

Menlo Park, Californla 94025

(415) 326.9400 Telex 704216 Fax (415) 326.8072

\title{
PRAISE ENHANCEMENTS TO INCLUDE GENERAL STRAIN HARDENING EXPONENTS \\ AND MID-LIFE RESIDUAL STRESS AND WATER CHEMISTRY CHANGES
}

June 7, 1990

Subcontract No. B098758

Prepared for

Lawrence Livermore National Laboratory

Livermore, California 94550 


\section{TABLE OF CONTENTS}

1.0 Introduction $\ldots \ldots \ldots \ldots \ldots \ldots \ldots \ldots \ldots \ldots \ldots \ldots \ldots \ldots, 1$

2.0 Characterization of Remedial Residual Stresses $\ldots \ldots \ldots \ldots \ldots \ldots .2$

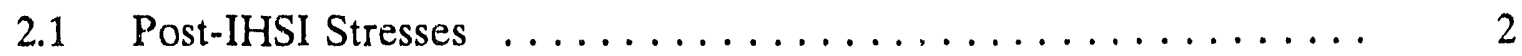

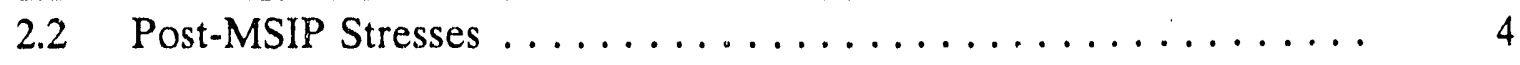

3.0 Mid-Life Changes in Operating Stresses, Water Chemistry, or Residual Stresses .......................... 13

4.0 New CERT Results for $304 \ldots \ldots \ldots \ldots \ldots \ldots \ldots \ldots \ldots \ldots \ldots, 14$

5.0 Expanded J-Solutions ......................... 17

6.0 PRAISE Pre- and Post-Processor ..................... 18

6.1 PRAISE Input-Processor (PR INPUT) $\ldots \ldots \ldots \ldots \ldots \ldots \ldots, 18$

6.2 PRAISE Post-Processor (PR_pLOT) ................ 18

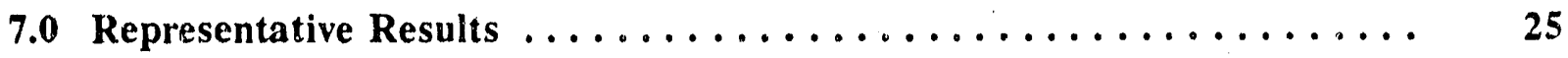

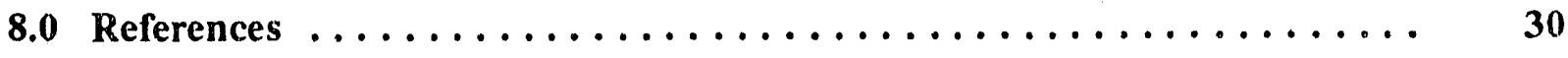

Appendix A: Detailed Formats for Input Cards $\ldots \ldots \ldots \ldots \ldots \ldots \ldots$ A-1

FaAA-SF-R-90-06-06 Page ii 


\subsection{INTRODUCTION}

The purpose of this document is to describe some recent changes made to the PRAISE Code to provide some additional capabilities. The major changes are associated with the new capability to analyze cases where there is a mid-life change in residual stresses and/or water chemistry. Such changes have been proposed as a means of improving the reliability of BWR piping by reducing the oxygen content of the coolant (or other favorable themistry changes) or altering the residual stresses near welds to provide a stress distribution less favorable to crack initiation and growth. Induction heating stress improvement (IHSI) and mechanical stress improvement process (MSIP) are considered, with the time at which the process is implemented defined by the user. As-welded residual stresses are considered to be present prior to the stress improvement treatment.

Improved pre- and post-processors were also developed and are described, which should be particularly useful to users of the PC version of PRAISE. In addition, improved J-integral solutions are incorporated that allow a treatment of general Ramberg-Osgood strain hardening, rather than the specific values of the strain hardening exponent included in earlier versions of the PRAISE Code.

This document discusses only the new additions to the code and is an addition to earlier documentation. Some example results are presented, and the Appendix provides a complete updated description of the input cards for the newly expanded PRAISE-CC Code.

FaAA-SF-R-90-06-06 


\subsection{CHARACTERIZATION OF REMEDIAL RESIDUAL STRESSES}

As-welded residual stresses often have a detrimental effect on the initiation and growth of stress corrosion cracks in sensitized weldments of BWR piping. Earlier versions of PRAISE contain default statistical distributions of residual stresses. It has been suggested that the residual stresses could be altered to become favorable, thereby improving the reliability of BWR piping. Two procedures have been proposed, induction-heating stress improvement (IHSI) and mechanical stress improvement process (MSIP). The resulting residual stress distributions will be characterized in this section.

\subsection{Post-IHSI Stresses}

The induction heating stress improvement (IHSI) process is suggested as one of the counter-measures for intergranular stress corrosion cracking (IGSCC) $[1,2]$. The process results in axial residual stresses that are compressive on the ID and, thus, are favorable for impeding stress corrosiun crack initiation and growth. The resulting residual stresses are also axisymmetric and self-equilibrating through the thickness.

References 1 and 2 provide experimental and analytical post-IHSI residual stress distributions through the wall. In the context of PRAISE, only the axial stresses are of interest here. These references contain results for $4,10,12,16$, and 26 inch lines. Based on the information available $[1,2,3]$, these stresses vary approximately linearly through the wall.

Post-IHSI stresses at the ID and OD were gathered from References 1 and 2 . When the stresses are linearly varying through the wall, axisymmetric and self-equilibrating, the stresses at the ID and OD are related to one another by the expression 


$$
\sigma_{\mathrm{ID}}=-\sigma_{\mathrm{OD}} \frac{3 R_{\mathrm{i}}+2 h}{3 R_{\mathrm{i}}+h}
$$

where $R_{i}=$ inside radius of the pipe

$\mathrm{h}=$ wall thickness of the pipe

Thirty-one sets of through-wall stresses were available. From these 31 sets of data, 62 values of stresses at the ID were obtained; 31 values directly, and 31 values using the OD data converted to ID values by use of the above equation. The post-IHSI stresses from References 1 and 2 were grouped in several different ways, and the mean and standard deviation for each group were calculated. The results are summarized in Table 1. For each of the categories (except the last one) shown in Table 1, the stresses were plotted in the

Table 1

Summary of Post-IHSI

Stresses at the ID

\begin{tabular}{|l|c|c|c||}
\hline \multicolumn{1}{|c|}{ Category } & $\begin{array}{c}\text { Number of } \\
\text { Data }\end{array}$ & $\begin{array}{c}\text { Mean } \\
(\mathrm{ksi})\end{array}$ & $\begin{array}{c}\text { Standard } \\
\text { Deviation } \\
(\mathrm{ksi})\end{array}$ \\
\hline All & 62 & -40.8 & 13.6 \\
\hline ID Data & 31 & -43.3 & 9.7 \\
\hline Projected from OD to ID & 31 & -38.4 & 16.4 \\
\hline All Experimental & 46 & -44.7 & 11.6 \\
\hline All Analytical & 16 & -29.9 & 13.2 \\
\hline All 4 Inch & 4 & -38.8 & 7.5 \\
\hline All 10 Inch & 10 & -29.2 & 16.3 \\
\hline All 12 Inch & 36 & -45.1 & 11.0 \\
\hline All 16 Inch & 10 & -41.5 & 13.5 \\
\hline All 26 Inch & 2 & -22.8 & 8.2 \\
\hline
\end{tabular}

FaAA-SF-R-90-06-06 
form of histograms with the normal distribution based on the calculated mean and standard deviation superimposed (Figure 1). In each of the categories, normal distribution seems to reasonably characterize the scatter present in the data.

Based on the results summarized in Table 1 and Figure 1, along with supporting results from References 1 and 2, it appears that the post-IHSI residual stresses can be adequately described as axisymmetric with a linear through-wall gradient. For a given pipe size and thickness, such a spatial distribution can be characterized by a single number, such as the value of the stress at the ID. The results of Figure 2 indicate that the statistical distribution of the ID residual stress is normally distributed, and the results of Table 1 show no consistent variation of the mean and standard deviation with pipe size. Hence, it is suggested that mean and standard deviation of post-IHSI residual stresses can be taken as the sum of all pipe sizes. The values corresponding to "all experimental" are suggested, which are a mean of $-44.7 \mathrm{ksi}$ and a standard deviation of $11.6 \mathrm{ksi}$.

The mean and standard deviation of the post-IHSI residual stresses are input by the PRAISE user. The values referred to immediately above are suggested for use.

\section{$2.2 \quad$ Post-MSIP Stresses}

The mechanical stress improvement process (MSIP) ccnsists of applying compressive stresses around the circumference on the outside of a pipe by applying a ring that squeezes a short portion of the pipe. The magnitude of the applied ring load is sufficient to produce permanent reduction of the diameter of the pipe under the ring, which produces compressive axial residual stresses on the ID that extend a short distance away from the location of the ring. This process can thus be used to produce favorable residual stresses in the vicinity of a circumferential weld to impede IGSCC.

References 4, 5, 6, and 7 provide analytical results for 4-, 10-, 12-, and 28-inch nozzles treated with MSIP. The through-wall stress distributions in the heat-affected zone (HAZ) (half-thickness away from weld centerline) on either side of the weld were obtained from

FaAA-SF-R-90-06-06

Page 4 

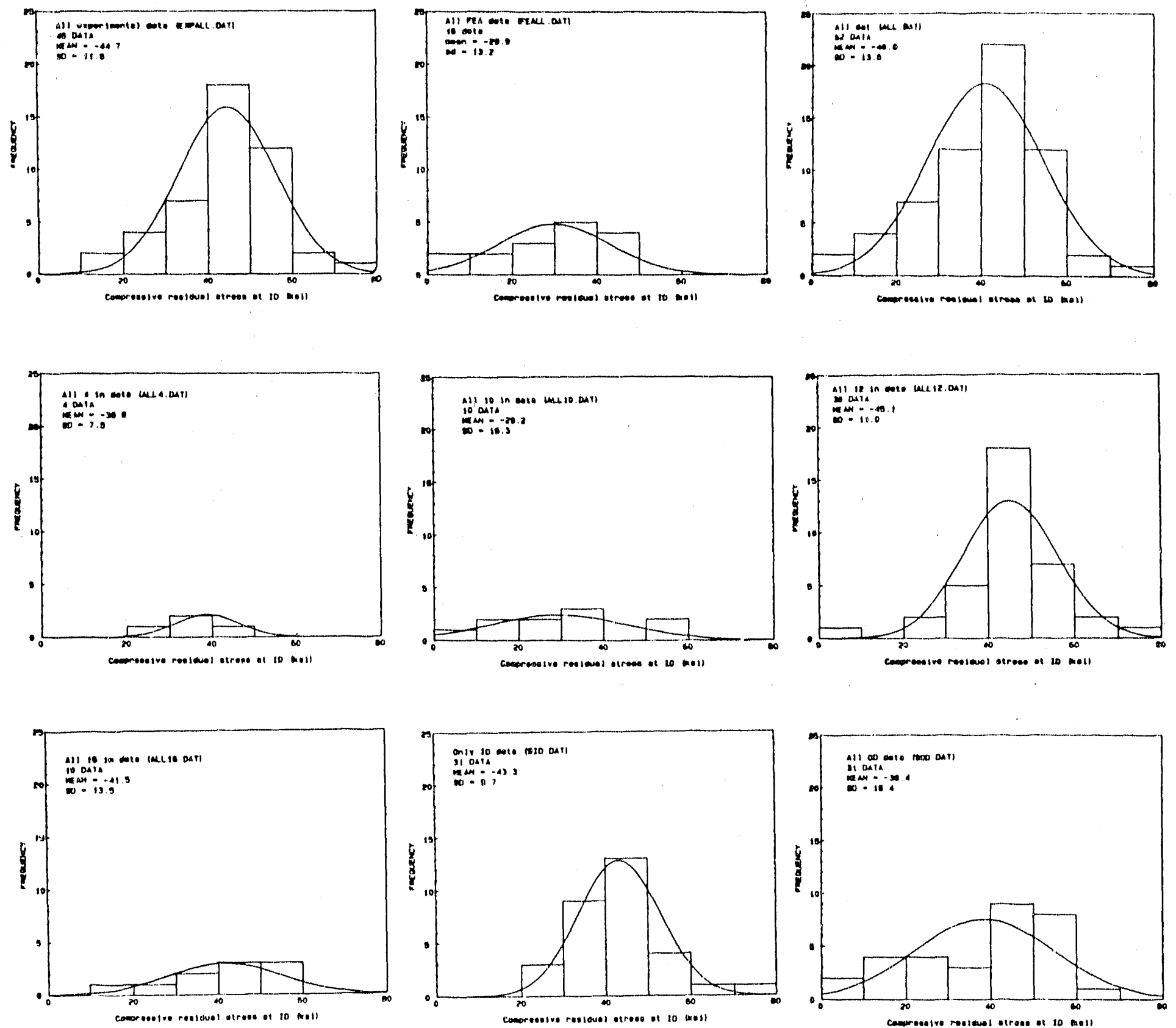

Figure 1. Distributions of post-IHSI $\sigma_{\mathrm{ID}}$ for various categories. 


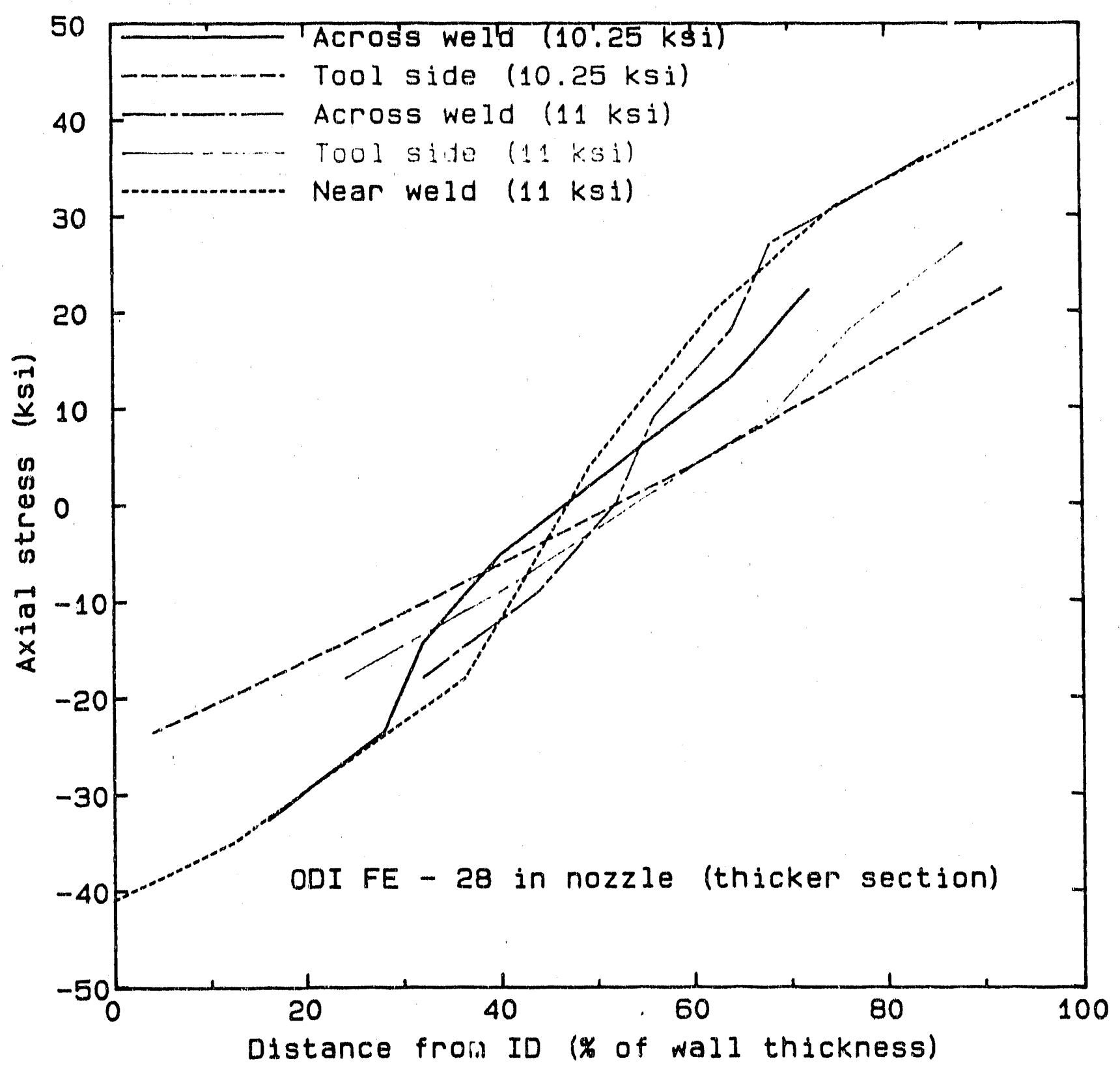

M3280DIT.DAT OR-0QT-1800

Figure 2. Post-MSIP stress distribution in the "thicker" section of a 28 inch nozzle (ODI FE results).

FaAA-SF-R-90-06-06

Page 6 
the color contour plots included in the references. Reference 8 contains experimental measurements of through-wall post-MSIP stresses in 12- and 28-inch lines in the region of the HAZ. The data forms in References 4-8 were collected and are summarized in Figures 2-7. Since the pipe is squeezed only on one side of the weld, the stresses in the HAZ between the weld and the tool is referred to as the "tool side," and the stresses in the HAZ on the other side of the weld is referred to as "across weld." The "ksi" values indicated in the tables and in the figures correspond to the average radial stress under the indenting ring. From Figures 2-7, the following is concluded:

1. The axial MSIP stresses in the HAZs of a weld can be characterized as linearly varying through the wall and axisymmetric. The stresses are therefore self-equilibrating through the wall and, knowing the stress on the ID and the pipe geometry, the through-wall stress distribution can be obtained.

2. The stresses on the ID are a function of the axial distance from the tool and are also a function of the applied compression under the tool. Generally, the stresses in the range of -20 to $-40 \mathrm{ksi}$ are produced on the ID of the pipe.

Based on the limited available information, it is not possible to statistically characterize the MSIP stresses. The through-wall stress distributions seem to be similar to those obtained by IHSI treatment. The post-MSIP stresses are input to PRAISE in a manner identical to the IHSI stresscis. 


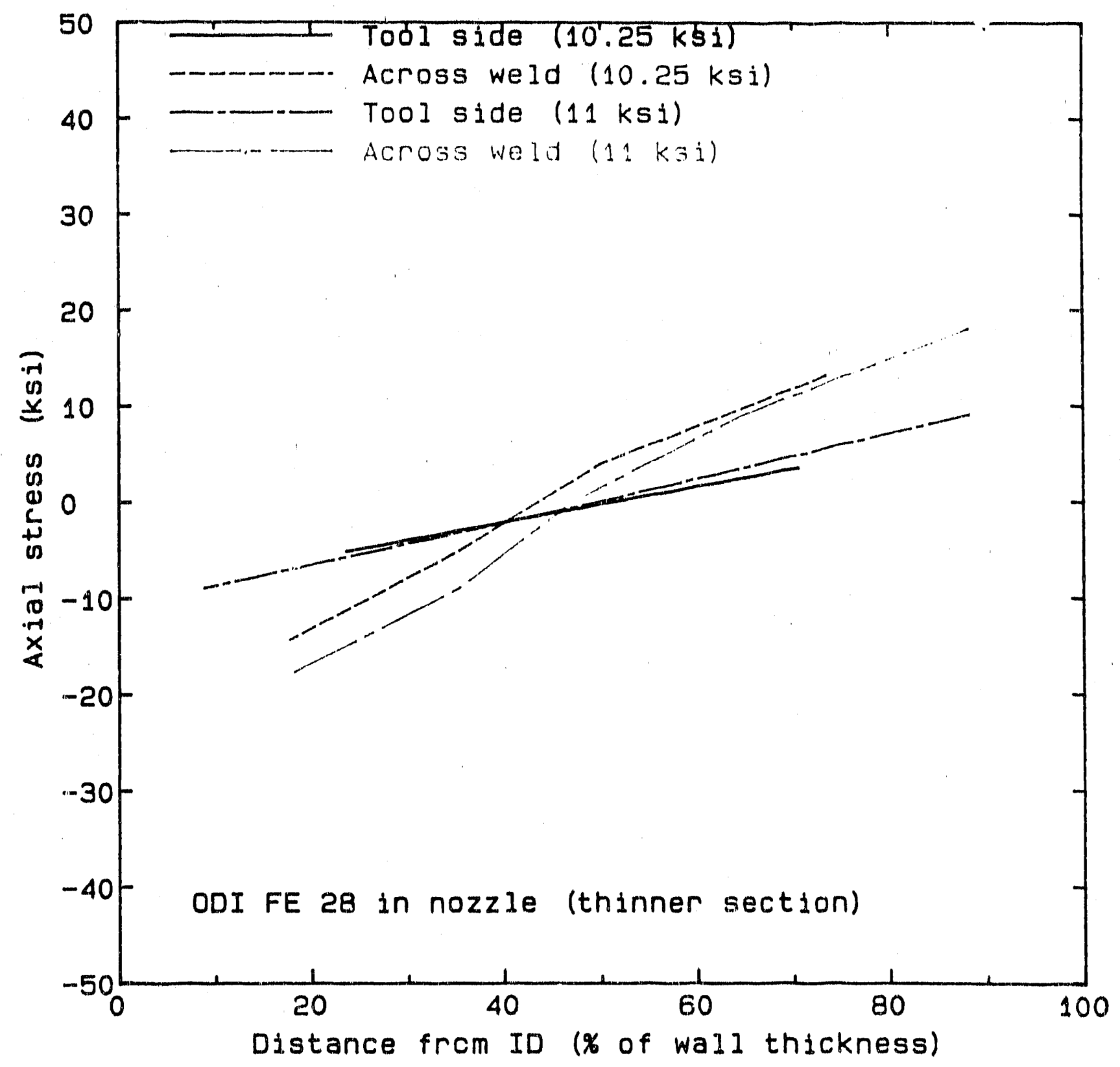

MGEBODI.DAT O2-06-1090

Figure 3. Post-MSIP stress distribution in the "thinner" section of a 28 inch nozzle (ODI FE results). 


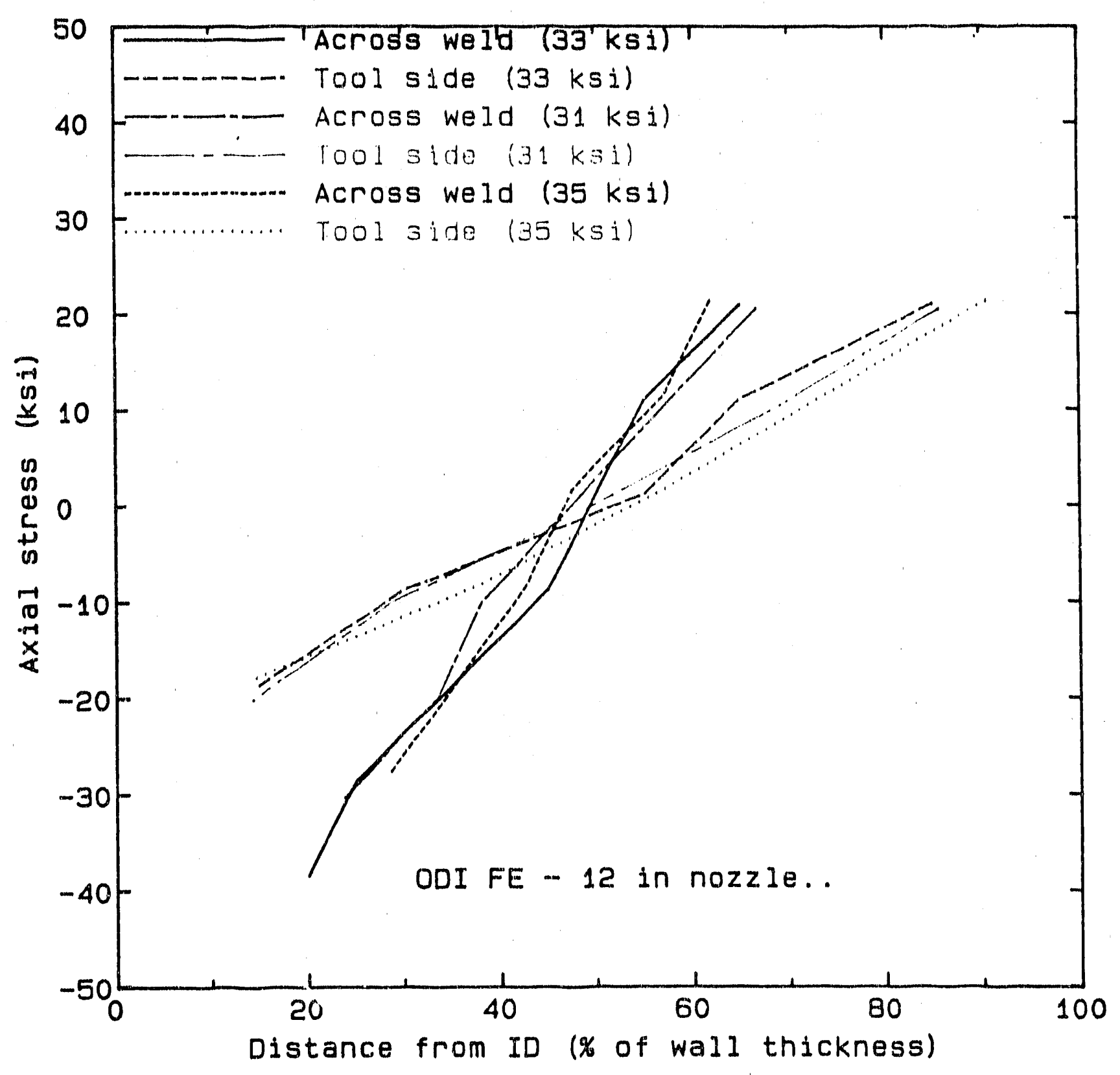

MS1200I.DAT 02-08-1000

Figure 4. Pcst-MSIP stress distribution in a 1.2 inch nozzle (ODI FE results). 


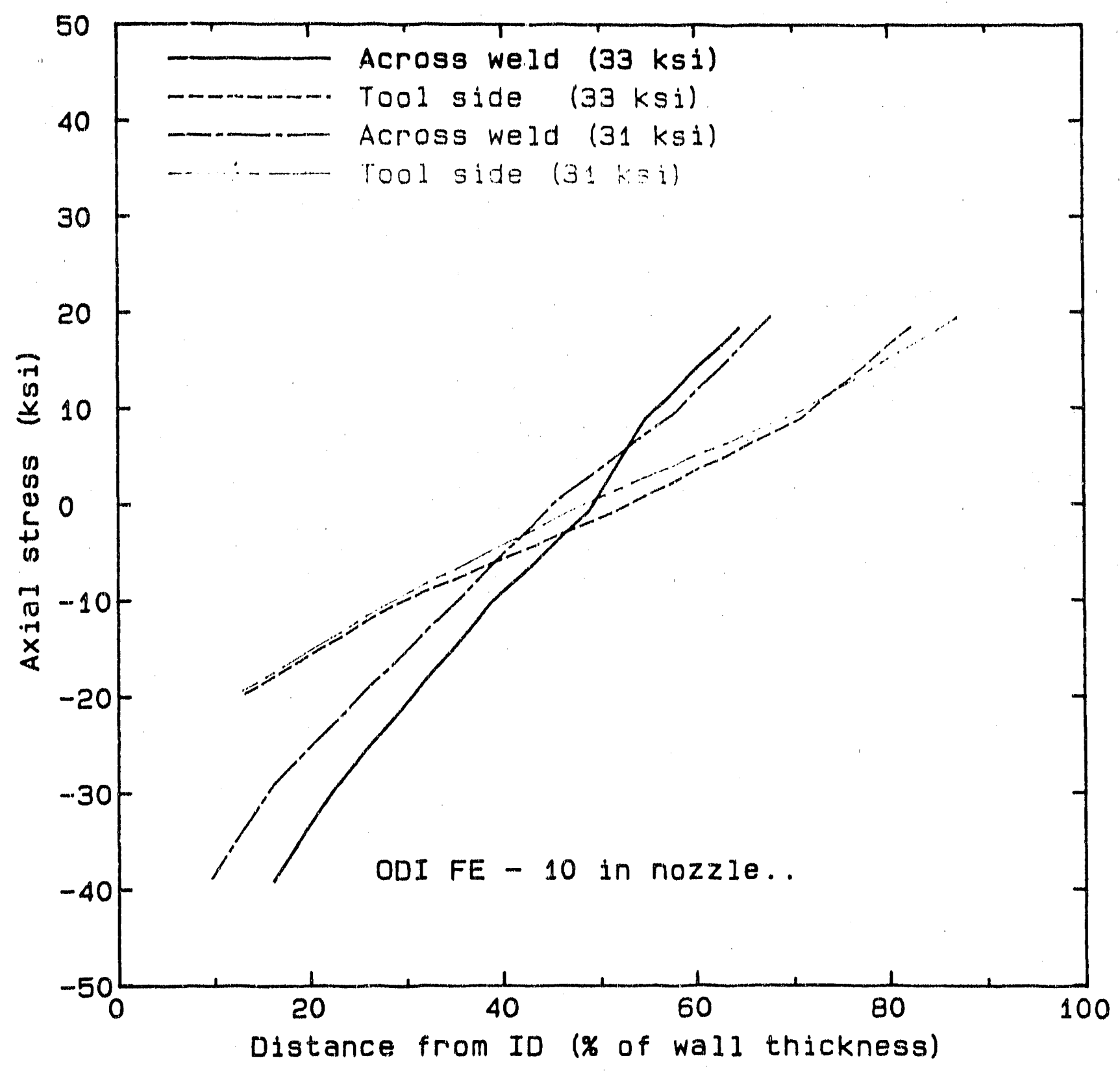

MB1000I.DAT O2-00-1000

Figure 5. Post-MSIP stress distribution in a 10 inch nozzle (ODI FE results). 


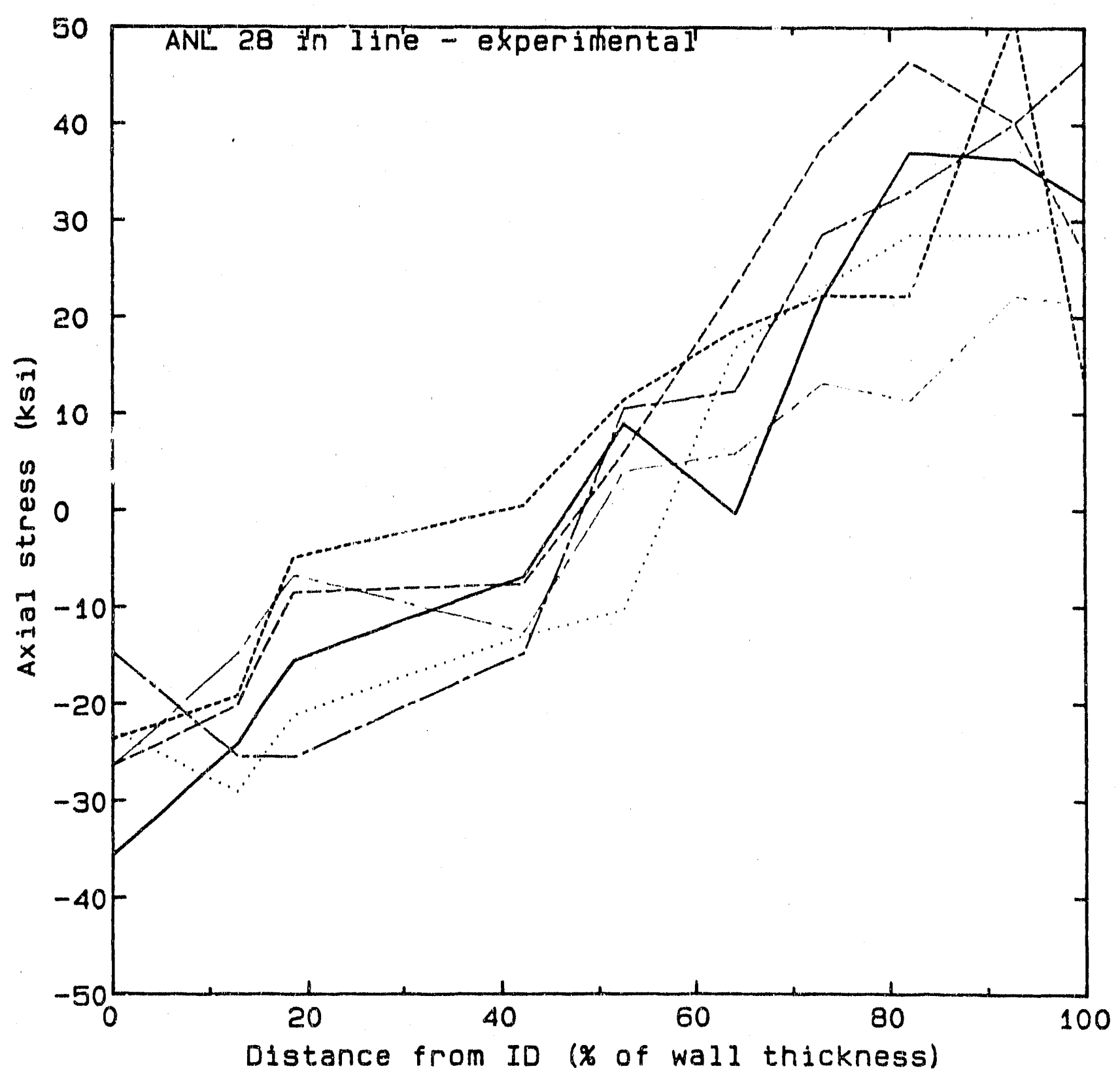

MEEXP.DAT 02-08-1900

Figure 6. Post-MSIP stress distribution in a 28 inch line (ANL experimental data). 


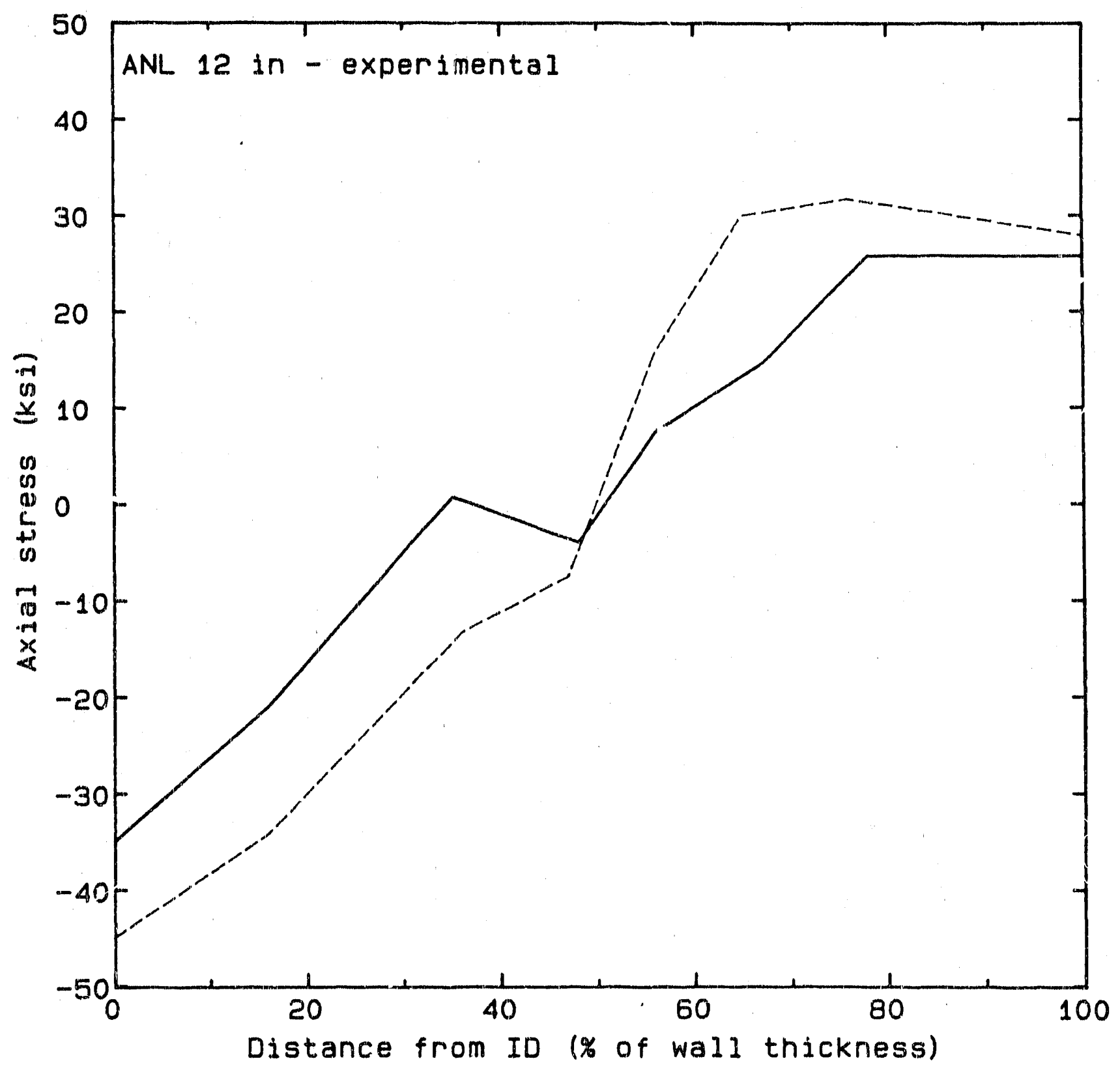

HI2EXP.DAT 02-08-\$000

Figure 7. Post-MSIP stress distribution in a 12-inch line (ANL experimental data). 


\subsection{MID-LIFE CHANGES IN OPERATING STRESSES, WATER CHEMISTRY, OR RESIDCAL STRESSES}

Provisions have been made in the PRAISE Code to change one or more of the operating parameters at any arbitrary time during the plant operation. This makes it possible to evaluate the effect of changes of these parameters on the leak and LOCA probabilities. The operating parameters that then can be changed at mid-life include the following:

1. Oxygen level at plant start-up

2. Oxygen level turing steady-state operation

3. Coolant conductivity

4. Deadweight stress

5. Deadweight and restraint of thermal expansion components of stress in the hot normal operating conditions

6. Vibratory stresses

7. Wall thickness of the pipe

8. Residual stress distributions; these can be changed to model IHSI or MSIP treatments

Changes in operating parameters can be made at a maximum of four occasions. Whenever a change in one of the above parameters is made, all the other parameters have to be respecified, whether or not they changed.

The PRAISE Code has been modified such that during each replication, the current values of the operating parameters are used for crack initiation and growth calculations. If wall thickness of the pipe is changed in mid-life, then the stresses due to pressure are recalculated. If the thickness is changed, the residual stress distributions are renormalized such that the stress is the same as before at any given fractional depth through the wall. If a change in residual stress is desired in mid-life, it can only be changed to axisymmetric selfequilibrating through the wall (MSIP or IHSI). 


\subsection{NEW CERT RESULTS FOR 304}

Additional crack initiation results for CERT tests [8] have become available since the last update [9] to the PRAISE Code. These results include the effects of chromates, oxygen scavengers, and organic acids on crack initiation and growth. The oxygen, temperature, conductivity, strain rate, and degree of sensitization for these tests are also reported. The results for time to initiation and crack velocity at initiation are plotted as a function of the damage parameter, $D_{6},[9]$ in Figures 8 and 9, respectively. The earlier results of Reference 9 are also plotted in the same figures. The effects of oxygen, temperature, conductivity, strain rate, and the degree of sensitization enter into the definition of $D_{6}$. From Figures 8 and 9, the new data appear to fall within the scatter band of earlier data $r \epsilon_{\text {, }}$ orted in Reference 9; and the effects of these new variables will not be explicitly considered in the PRAISE Code. 


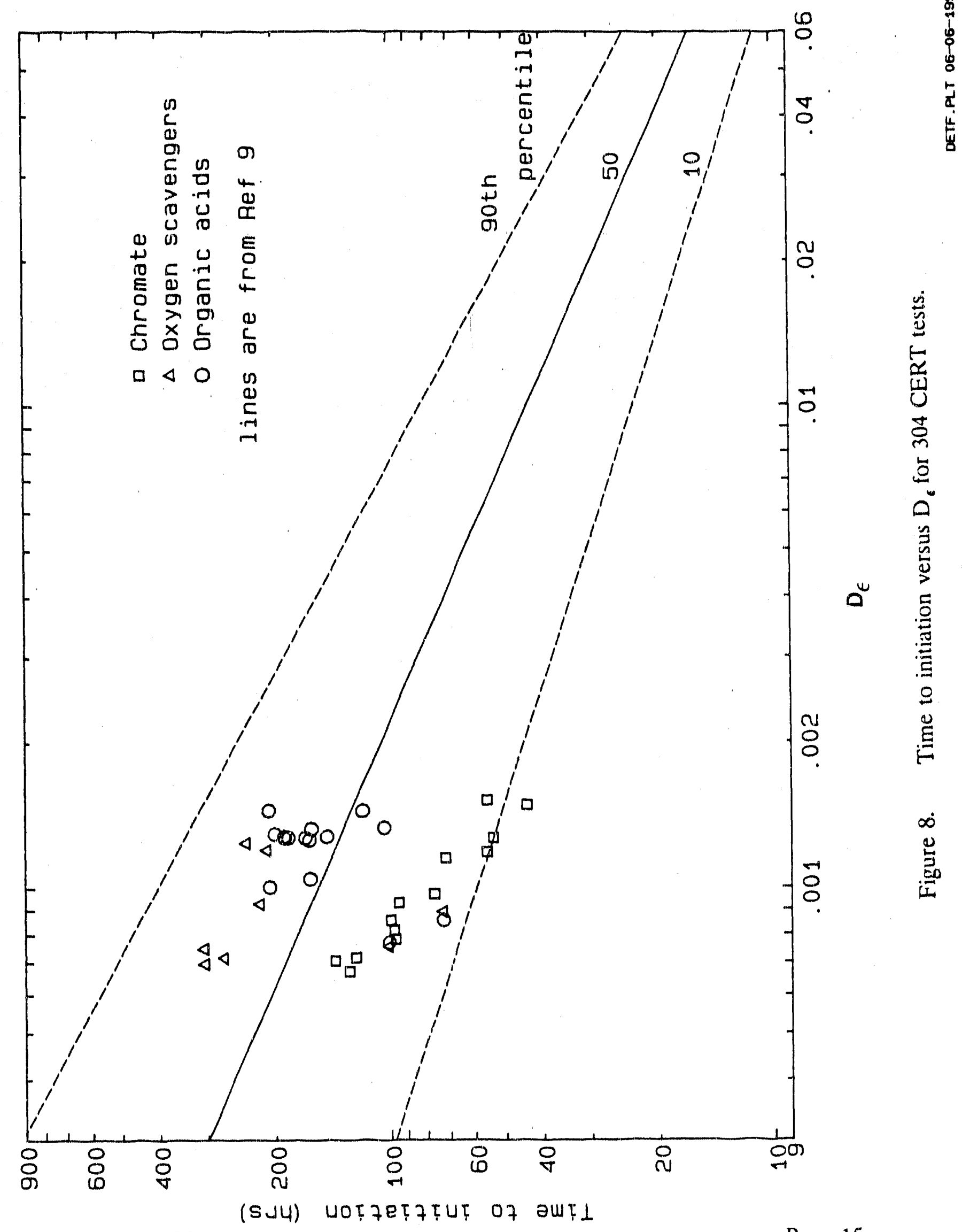

FaAA-SF-R-90-06-06

Page 15 


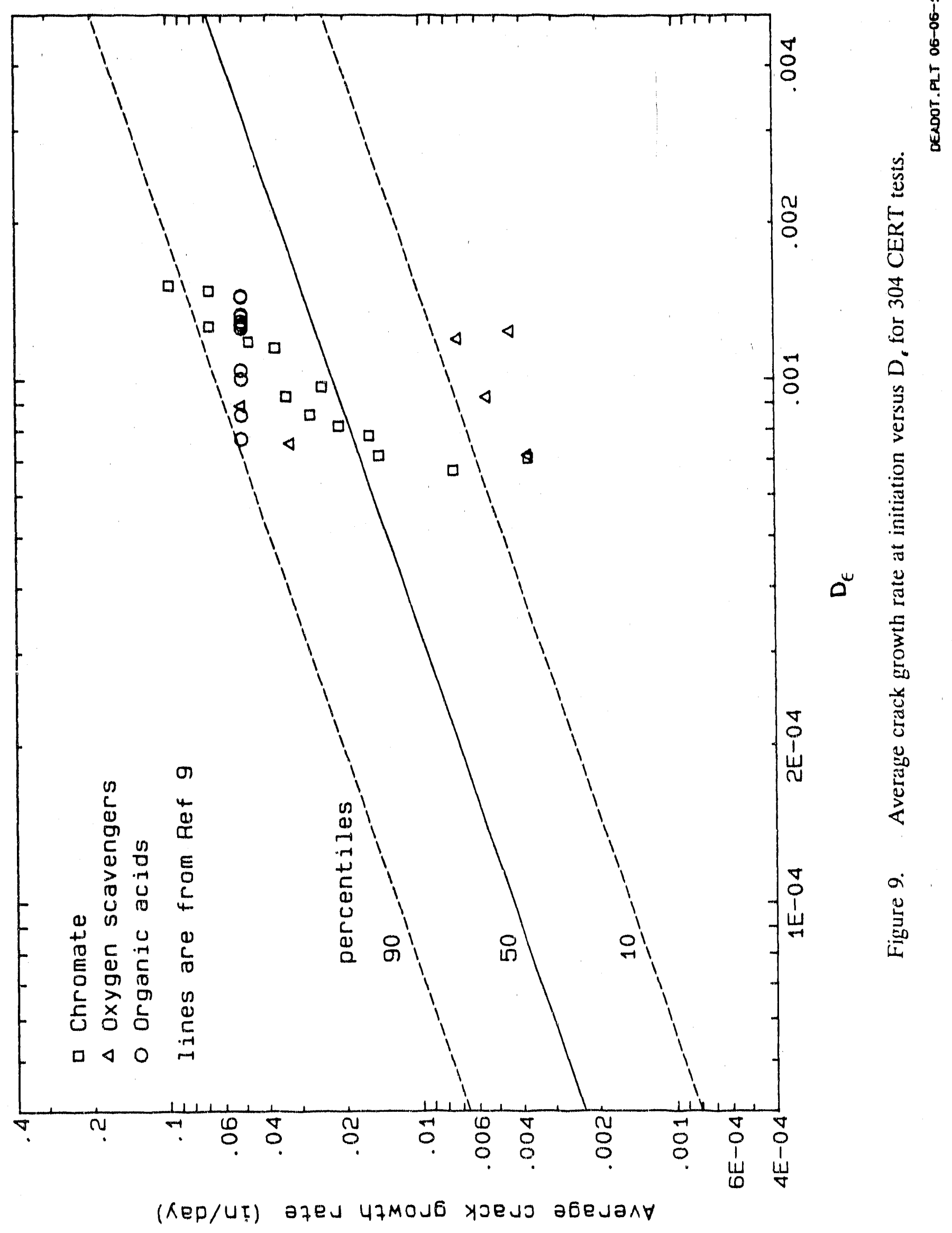

FaAA-SF-R-90-06-06

Page 16 


\subsection{EXPANDED J-SOLUTIONS}

The existing version of the PRAISE Code [9] contained J-solutions for complete circumferential and through-wall cracks that were used for the elastic-plastic failure criteria. The J-so' $\lrcorner$ tions for both of these crack models were valid only for strain hardening exponent (n) of 5 and for $\mathrm{R}_{\mathrm{i}} / \mathrm{h}$ ratios of 5 and 10 . The $\mathrm{J}$-solutions in the current version have now been expanded to be valid for a range of $n$ values. The exponent, $n$, is now a user-input variable. The implementation of the new J-solutions is described in Reference 10. The following is the range of validity of these J-solutions.

\begin{tabular}{lcc} 
& $\begin{array}{c}\text { Cor.uplete Circumferential } \\
\text { Crick }\end{array}$ & $\begin{array}{c}\text { Through-Wall } \\
\text { Crack }\end{array}$ \\
\cline { 2 - 3 } Crack Depths & $0.125 \leq \mathrm{a} / \mathrm{h} \leq 0.75$ & $0.0625 \leq(\mathrm{a} / \pi \mathrm{R}) \leq 0.5$ \\
$\mathrm{R}_{\mathrm{d}} / \mathrm{h}$ & $5,10,20$ & $5,10,20$ \\
Exponent, $\mathrm{n}$ & $1-10$ & $1-7$
\end{tabular}

The $J$-solutions are available for discrete values of crack depths, $n$, and $R_{i} / h$ ratios. For crack depth and $\mathrm{n}$, bi-cubic spline interpolation or extrapolation is used to get $\mathrm{J}$-values for any arbitrary input values of crack depth and $n$. No interpolation is performed on $R_{i} / h$; instead the nearest value is used.

FaAA-SF-R-90-06-06 


\subsection{PRAISE PRE- AND POST-PROCESSORS}

Pre- and post-processors that have been developed to aid the user in running the code are described in the following subsections.

\subsection{PRAISE Input-Processor (PR_INPUT)}

PR_INPUT is a utility to aide the user in setting up a PRAISE input file. It prompts the user to input values of the variables, one at a time. It displays the current value of the variable and also the valid range for the variable. When the PR-INPUT command is invoked, it first prompts the user with an option to read a template file. [A template file (extension.TPL) is a binary file containing the input data that are processed by PR_INPUT. A template file is written by the input processor at the end of the run.] If a template file is specified by the user, all the variables are initialized to values stored in the template file. Next, the processor requests inputs generally in the same order as they appear in Appendix A. A typical prompt for input is as follows:

Fallure Criterla (IFAILC)

$0:$ Net-section stress

$1:$ Jlc, Tmat exceedance

$2:$ Both

The current value is 0 [valid range is $>=0$ and $<=2$ ]

Press ENTER to accept the current values, or Enter a new value.

For every prompt, the input-processor displays the FORTRAN variable name of the requested input as well as the valid range of inputs. The input-processor requests only the information required for the selected analysis and, if necessary, fills in the PRAISE compatible input file with dummy values. For example, the input processor will request the values of $\mathrm{J}_{\mathrm{Ic}}$ and $\mathrm{T}_{\mathrm{mat}}$ only if the selected failure criteria requires those values (IFAILC = 1 or 2$)$.

The input-processor expects the following group of inputs, each of which requires a large number of data, to be saved in a file. The input processor requests the name of the file and then includes the file in a PRAISE input file. These groups of inputs are as follows: 
1. Stratification. If the user selects to input coordinates of each cell (ISQARE $=0$ ), then the user is expected to create a file containing the information requested on Card $5 \mathrm{~A}$.

2. Stress Intensity Factors for Radial Gradient Thermal Stresses. If more than one transient (KTYPES > 1) are to be considered in the analysis, the tabular inputs required on Cards $6 \mathrm{E}$ through $6 \mathrm{~F}$ should be contained in a file.

3. Seismic Data. If seismic events are to be considered in the analysis (NQUAKE $=1$ ), then the inputs required on Cards $7 \mathrm{~A}$ and $7 \mathrm{~B}$ should be contained in a file.

4. Residual Stresses. If the user selects the residual stress option (ISIGRS $=1$ ), it requires coefficients of the polynomials defining the contribution of residual stresses to the stress intensity factors. The inputs required on Cards $6 \mathrm{G}$ and $6 \mathrm{H}$ should be saved in a file.

When all the inputs are completed, the input-processor prompts the user to enter file names for storing data in a template file and in a PRAISE-compatible input file.

\subsection{PRAISE Post-Processor (PR_PLOT)}

PR_PLOT is a plotting progiam to provide plots of leak and LOCA probabilities and also to display stratification maps with number of samples and failures from each stratum. The program is invoked as follows:

\section{PR_PLOT FNAME}

where FNAME is the file name (without the extension). The program then searches for files FNAME.SLK, FNAME.BLK, FNAME.LOC, and FNAME.STT, and displays the plot selection menu, which typically looks as follows:

FaAA-SF-R-90-06-06 


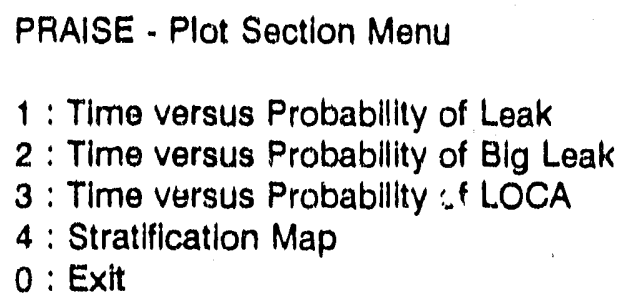

Make a selection (Enter a number) ?

If plot option 1, 2, or 3 is selected, the following menu appears:

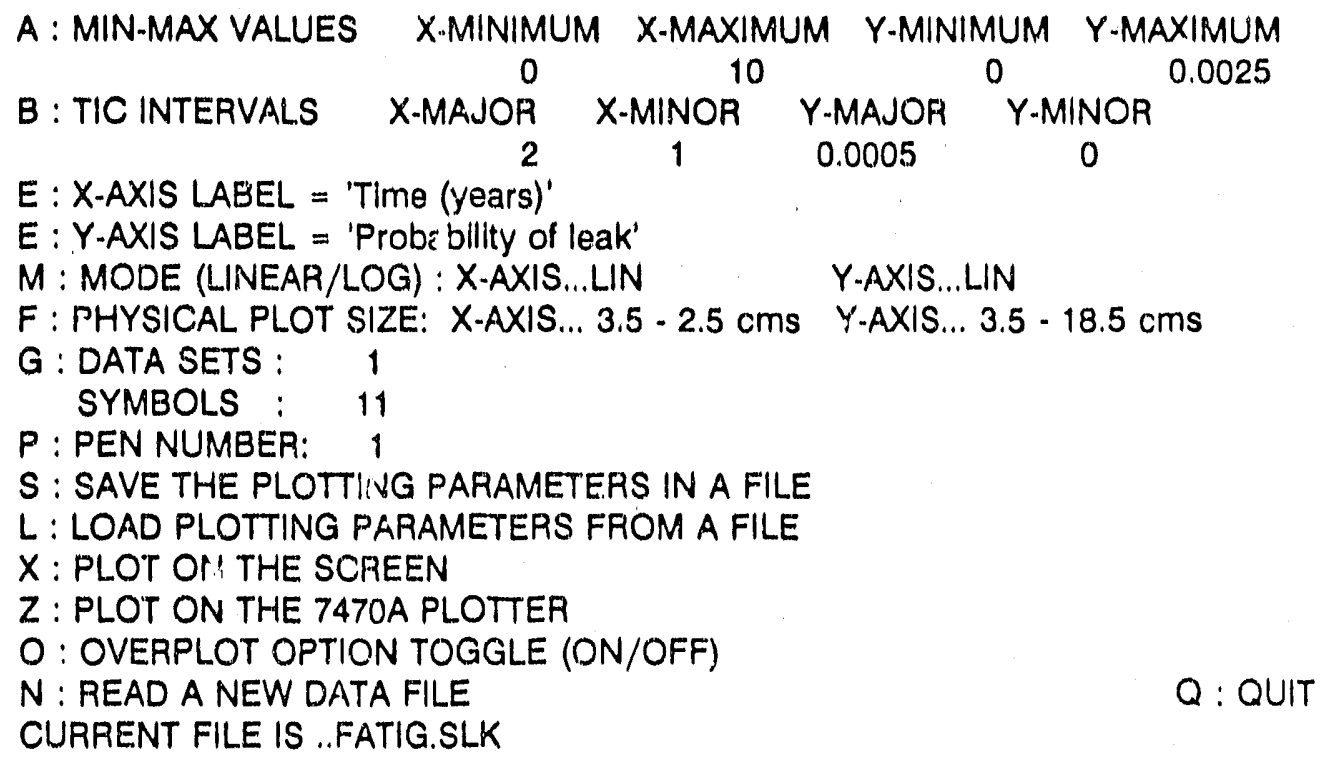

Enter desired option to change format or to plot

When this nienu appears, a plot can be made on the screen by entering $X$ (or $Z$ for plotting on a pen plotter). Any of the parameters listed on this menu can be changed by entering the corresponding letter that appears in the first column. A brief description of each of the options follows:

Min-Max Values (A) -. By default, the minimum and maximum values of data are used as plotting limits. When this option is selected, the user will be prompted to enter minimum and maximum limits for plotting on the $\mathrm{X}$ - and Y-axes. Data that fall outside these plotting limits will not be plotted. 
Tic Intervals (B) - B $y^{\prime}$ default, there are five major tic intervals on each axis where labels are printed. Also by default, five minor tics are drawn between two major tic intervals. These can be redefined by the user. To completely suppress minor tics, enter the minor tic interval as 0 (zero).

Axis Labels (E) -- This option can be used to redefine axis labels. Both upper and lower case characters can be used.

Plotting Mode (M) -- One of the following four plotting modes car be selected:

1. linear on $\mathrm{X}$, linear on $\mathrm{Y}$

2. linear on $X, \log$ on $Y$

3. $\log$ on $X$, linear on $Y$

4. $\log$ on $\mathrm{X}, \log$ on $\mathrm{Y}$

By default, both axes are plotted on a linear scale.

Physical Plot Size (F) -- This option is applicable only to pen plotters. By selecting this option, the physical size of the plot can be defir.ed in terms of dimensions of X-and Y-axis and coordinates of the lert-bottom corner of the plot with reference to a 8-1/2 $\times 11$-inch paper in landscape mode.

Symbols (G) -- A set of ten discrete symbols and ten different types of lines are provided. By selecting this option, the user can reassign symbols to data sets.

Pen Number (P) -- This option is applicable only to multi-pen plotters like the HP7470A plotter. By selecting this option, different colors can be assigned to data sets.

Save Plotting Parameters in a File (S) -- When this option is selected, the user will be prompted to enter a file name for saving the plotting parameters. The parameters saved are -- minimum and maximum plotting limits, tic intervals, axes labels, plotting mode, physical plot size, assigned symbols, and pen numbers.

FaAA-SF-R-90-06-06

Page 21 
Load Plotting Parameters from a File (L) -- By selecting this option, the user can recall the plotting parameters that were saved using the "S" option. A file name is requested from the user when this option is selected.

Plot on the Screen (X) -- This option is used to plot the data on the screen.

Plot on a Pen Plotter (Z) -- This option is used to plot the data on a HP7470A or compatible pen plotter. Follow the instructions that appear on the screen.

Overplot Option (O) -- This option is applicable only for the pen plotters. By default, the overplot option is turned off. When the overplot option is turned on, tics, labels, and axes are not plotted.

Read a New Data File (N) -- This option is used to select another file for plotting. When this option is selected, display returns to Plotting File Menu, from which another plot file can be sels cted.

Quit (Q) -- This option is used to EXIT from the plotting program.

If option 4 is selected from the plot selection menu, a color-coded stratification scheme as shown in Figure 10 is displayed. By default, leak results are provided. If all the samples from a stratum resulted in a leak, the cell is painted red; if no leaks occurred for a stratum, it is painted green; if some leaks occurred, the stratum is painted yellow. At the bottom of the screen, six options are listed for altering the display or for exiting to the plot selection menu.

Option A (New Scale): By selecting this option, a selective display of the stratification map can be obtained. The user is promoted to enter new limits of $a / b$ and $a / h$ for display.

FaAA-SF-R-90-06-06 


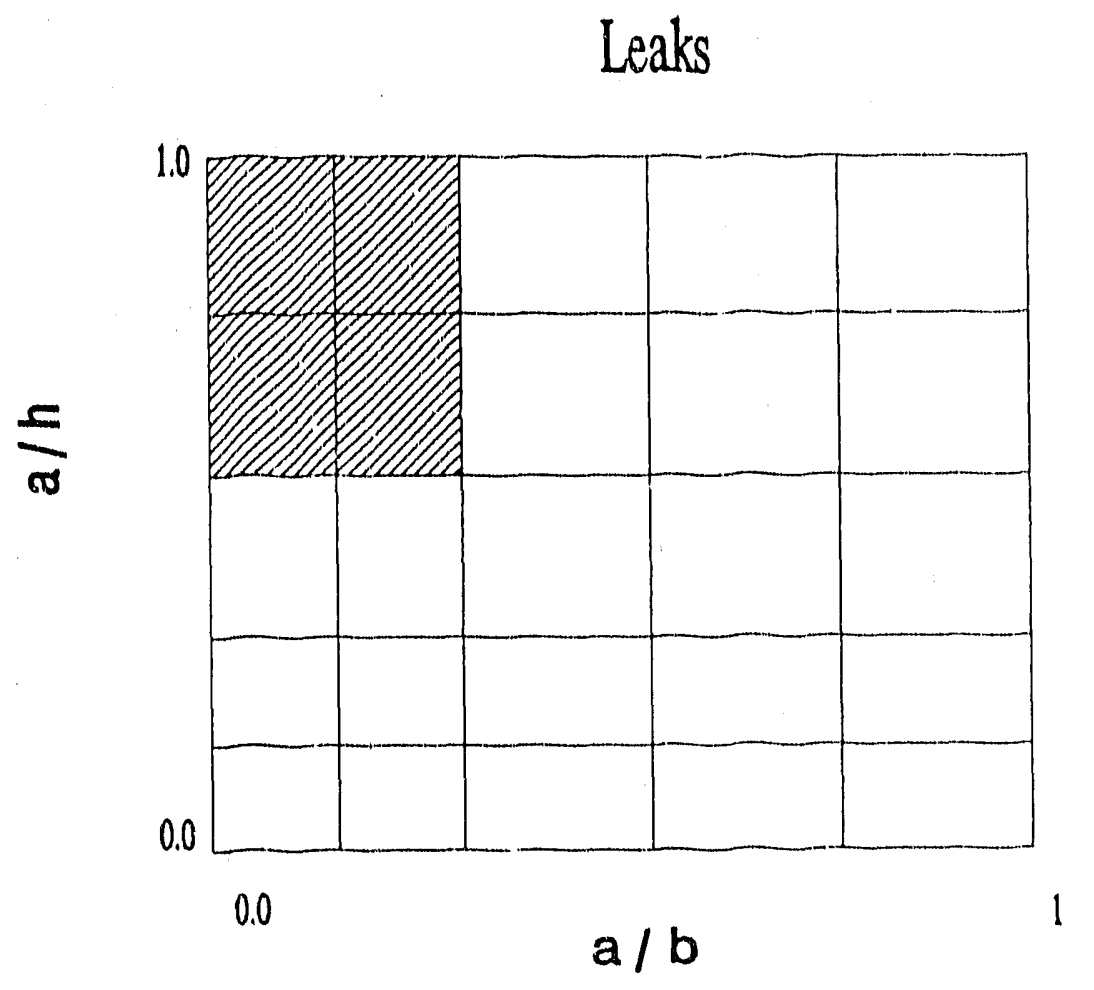

A: New Scale B: Leaks C: Big Leaks D: LOCA N: Numbers On/Off Q: Quit

Figure 10. A typical display of leak results on the stratification map.

FaAA-SF-R-90-06-06

Page 23 
Option B (Leaks): This is the default display. When this option is selected, the results of leaks are displayed.

Option C (Big Leaks): When this option is selected, the results of big leaks are displayed.

Option D (LOCA): When this option is selected, the results O: LOCA are displayed.

Option N (Numbers On/Om): When this option is selected, the user is provided with options to display any or all of the following:

Number of samples in each cell.

Number of failures (leaks, big leaks, or LOCA) in each cell.

Stratum number.

By default, none of these are displayed when the display is first generated.

Option Q (Quit): This option is selected to return to the plot selection menu.

The program does not have the capability to generate a hard copy of the stratification display on a pen-plotter. A hard copy of the display can be obtained by a graphics-dump of the screen if a compatible printer is connected to the computer. 


\subsection{REPRESENTATIVE RESULTS}

The new capabilities incorporated into the PRAISE Code for changing operating conditions during mid-life were exercised to generate leak probabilities. The base case inputs considered for all the results presented in this section are summarized below:

- $\quad$ Small lines $\left(\mathrm{R}_{\mathrm{i}}=1.91\right.$ inch, $\mathrm{h}=0.34$ inch $)$

- $\quad$ SCC initiated cracks only (304 properties)

- $\quad$ Maximum number of cracks at a weld $=6$

- $\quad$ Fatigue crack growth coefficient (C) normally distributed

$$
\begin{aligned}
\mathrm{C}_{50} & =9.14 \times 10^{-11} \\
\mathrm{C}_{90} & =3.5 \times 10^{-11} \\
\mathrm{~m} & =4 \\
\Delta \mathrm{K}_{\mathrm{th}} & =4.6
\end{aligned}
$$

- Flow stress normally distributed

$$
\begin{aligned}
& \text { Mean }=43.0 \\
& \text { Standard Deviation }=4.2
\end{aligned}
$$

- PSI, No ISI

- $\quad$ Detectable leak $=3 \mathrm{gpm}$

- $\quad$ No vibratory stresses

- Residual stress for small lines

- $\mathrm{O}_{2}$ at start-up $=8 \mathrm{ppm}$

- $\quad \mathrm{O}_{2}$ at steady-state $=0.2 \mathrm{ppm}$

- Steady-state temp $=560^{\circ} \mathrm{F}$

- $\quad$ Coolant conductivity $=0.2 \mu \mathrm{s} / \mathrm{cm}$

- Heat-up duration $=5$ hrs.

- Deadweight stress $=0.95 \mathrm{ksi}$

- $\quad$ DW + TE stresses $=8.02 \mathrm{ksi}$

- Operating pressure $=1.33 \mathrm{ksi}$

- $\quad$ Proof pressure $=1.56 \mathrm{ksi}$

Starting with this base case, the , llowing variables were changed during mid-life (at 20 years in all the cases):

1) Steady-state and starting oxygen

2) Dead weight and thermal expansion stresses

3) Residual stresses

Figure 11 presents effects of reducing dissolved oxygen level during mid-life on the leak probabilities. Reducing the steady-state oxygen from 0.2 to $0.05 \mathrm{ppm}$ decreases the cumulative probability of leak at 10 years by a factor of two. A change in the oxygen level during plant loading has much less influence on leak probabilities. The effect of lowering 


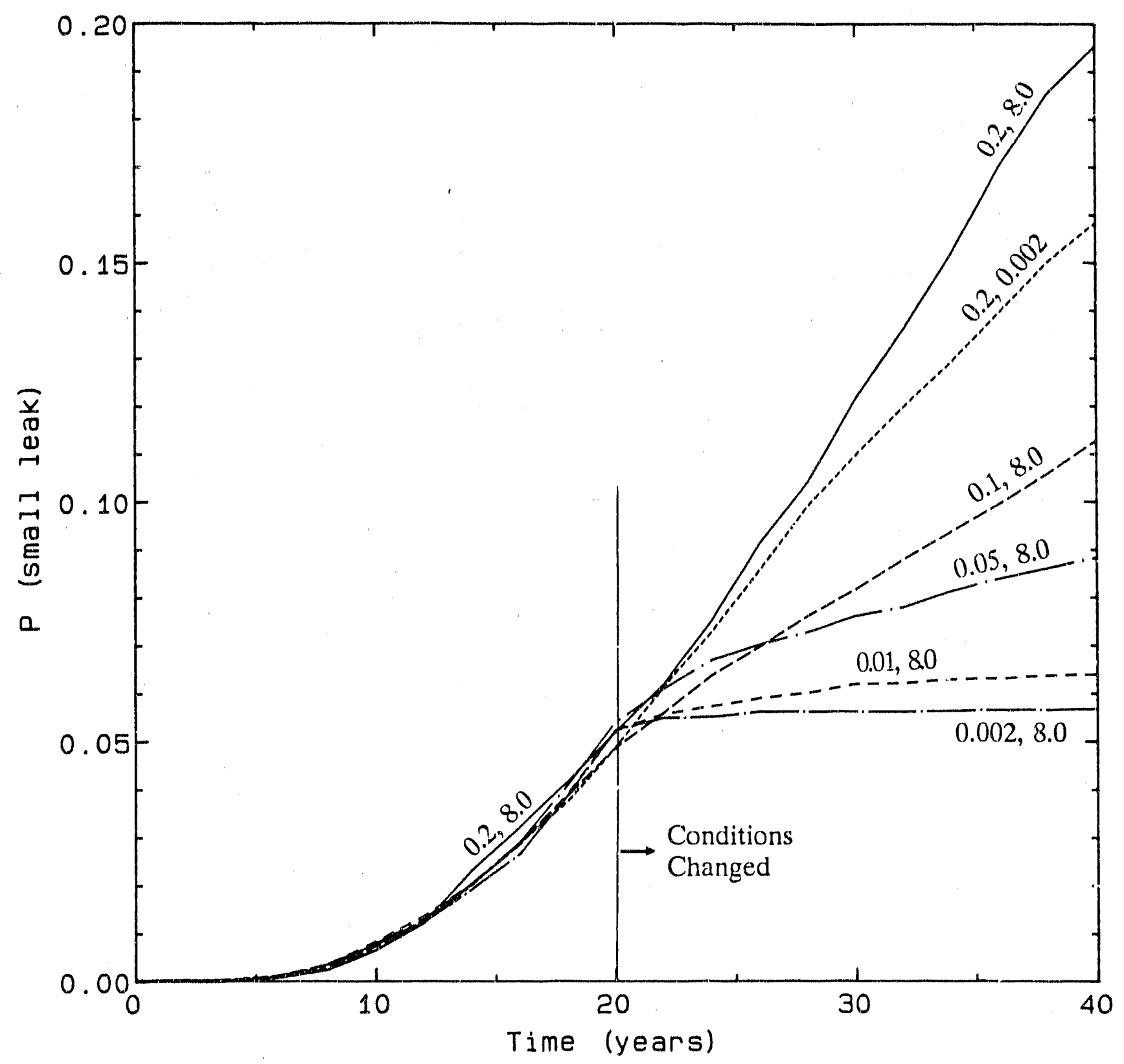

PAT 420A. SLK 08-06-1990

Figure 11. Effect of lowering oxygen at 20 years. The two numbers by each line are the oxygen concentration (ppm) in the coolant during plant start-up and steady state operation, respectively. 
operating stresses on the leak probabilities is shown in Figure 12. Results are presented for the cases when the dead weight and thermal expansion stresses were reduced by a factor of two.

Figure 13 presents results for the cases where residual stresses were changed by IHSI or MSIP treatm:nt to obtain linearly varying; axisymmetric residual stresses in the weld region. The distribution of these residual stresses is defined by specifying the mean and standard deviation of the stresses on the ID of the pipe. The recommended post-IHSI stress distribution based on the data analyzed in this report (mean $=-4.4 .7 \mathrm{ksi}$, standard deviation $=11.6 \mathrm{ksi}$ ) has a large effect on reducing the leak probabilities following the IHSI treatment. 


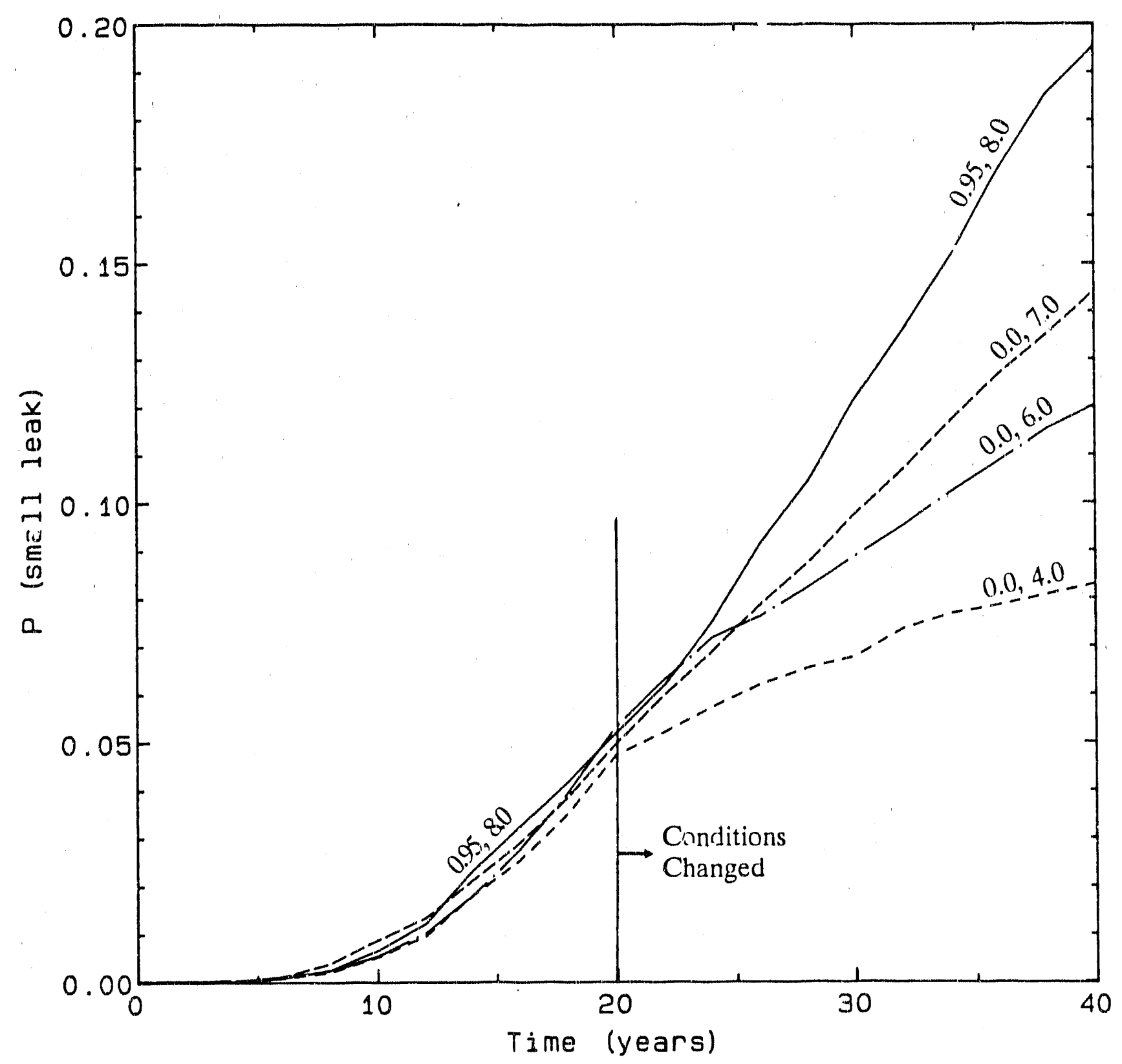

PAI 42SA . SLK O6-0B-1990

Figure 12. Effect of lowering operating stresses at 20 years. The two numbers by each line are the DW and DW + TE during steady-state operation, respectively. 


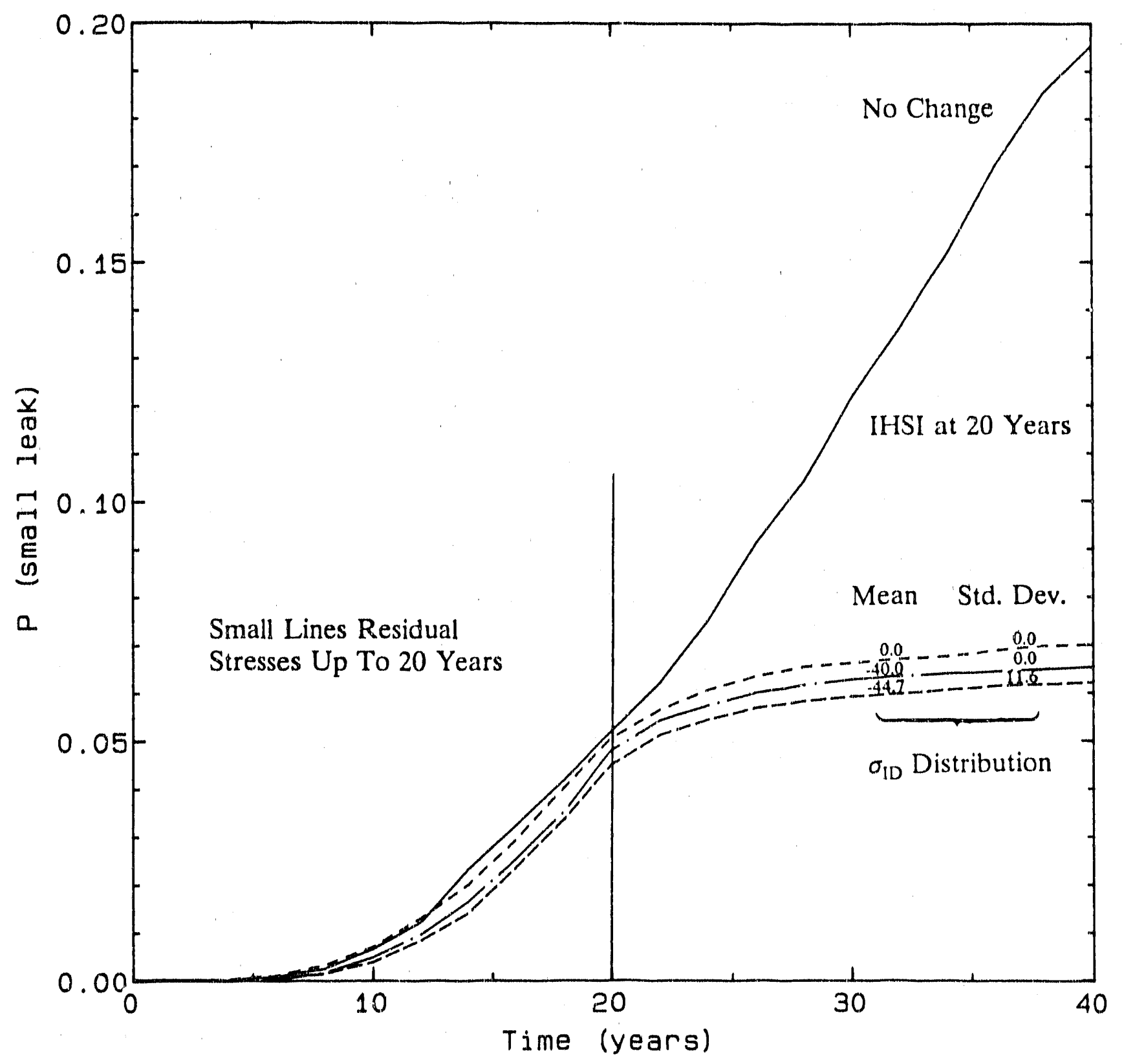

PAT 42AA. SLK 08-06-1990

Figure 13. $\quad$ Gffect of changing residual stresses during mid-life. 


\subsection{REFERENCES}

1. H.P. Offer, "Induction Heating Stress Improvement," Electric Power Research Institute Report NP-3375, November 1983.

2. E.F. Rybicki, et al., "Computational Residual Stress Analysis for Induction Heating of Welded BWR Pipes," Electric Power Research Institute Repoi: NP-2662-LD, December 1982.

3. N.R. Hughes, T.P. Diaz, and V.V. Pestanas, "Qualification of Induction Heating Stress Improvement for Mitigation of Stress Corrosion Cracking," Transactions of the ASME, Jourinal of Pressure Vessel Technology, Vol. 104, pp. 344-350, November 1982.

4. "Analytical Verifiuation of the Mechanical Stress Improvement Process for 4-Inch Nozzle," Report No. 1909-404-001-00, O'Donnell \& Associates, Pittsburgh, Pennsylvania, January 1988.

5. "Analytical Verification of the Mechanical Stress Improvement Process for 10-Inch Nozzle," Report No. 1909-404-001-00, O'Donnell \& Associates, Pittsburgh, Pennsylvania, January 1988.

6. "Analytical Verification of the Mechanical Stress Improvement Process for 12-Inch Nozzle," Report No. 1909-404-001-00, O'Donnell \& Associates, Pittsburgh, Pennsylvania, January 1988.

7. "Analytical Verification of the Mechanical Stress Improvement Process for 28-Inch Nozzle," Report No. 1909-404-001-00, O'Donnell \& Associates, Pittsburgh, Pennsylvania, January 1988.

8. Private communication between W.J. Shack, Argonne National Laboratory, and D.O. Harris, Failure Analysis Associates, Inc., December 1989.

9. D.O. Harris, D.D. Dedhia, E.D. Eason, and S.D. Patterson, "Probability of Failure in BWR Reactor Coolant Piping," NUREG/CR-4792, Vol. 3, 1986.

10. NASCRAC M.- NASA CRack Analysis Code, User's and Theory Manuals, Version 2.0, Failure Analysis Associates ${ }^{\circledR}$, Inc., Palo Alto, California, 1989. 


\section{Appendix A}

\section{Detailed Formats for Input Cards}

Detailed descriptions of the input cards read by PRAISE-CC are given in this section. The name, position on the card, format, and description of each variable are given. 
CARD TITLE CARD

READ Always

VARIABLE COLUMNS FORMAT

TITLE

$1-80$

$10 \mathrm{~A} .8$

DESCRIPTION

Problem description. 
CARD PROBLEM CONTROL VARIABLES

ID

OB

READ Always

VARIABLE COLUMNS FORMAT

INCIAT

$1-5$

I5

IFAILC

$6-10$

15

$11-15$

$16-20$

IREPLS

$21-25$

$26-30$

IREPAR

BNDRY

$31-40$

F10.3

15

15

\section{DESCRIPTION}

0: Run for pre-existing cracks. Include initiated cracks only if the sampled crack is below the BNDRY.

1: SCC initiated cracks only.

2: Pre-existing cracks only.

Failure criteria to be used:

0 : Net section fálure.

1: $\mathrm{J}_{\mathrm{Ic}}, \mathrm{dj} / \mathrm{da}$ exceedance.

2: Both.

Stress corrosion crack initiation sites.

Number of replications for crack initiation problem (not used for INCIAT $=0$ ).

0: Default to pre-existing cracks only.

$=0: \quad$ Leakers not repaired.

$=1$ : Leakers that are detected are repaired.

At the time of repair, all leakers are repaired.

Boundary in terms of a/h, above which initiated cracks are not included. For example,

1.1: Initiated cracks will always be included.

-0.1: Initiated cracks will never be included.

MTTYPE $\quad 41.45$

I.

Material type.

$=1: \quad 304$

$=2: \quad 316 \mathrm{NG}$

ISEED

$46-60$

Seed for the random number generator. 
CARD PROBLEM CONTROL VARIABLES (Cont'd)

READ Always

ID $\quad \mathbf{O B}$

VARIABLE COLUMNS FORMAT

IREMED $\quad 61-65$

I5

\section{DESCRIP'TION}

Number of future remedial actions (change in water chemistry, IHSI, weld overlays, etc.). 
VARIABLE

NTRIES

$1-5$

ISQARE

$6-10$

KTYPES

$11-15$

KRKDIS
I5

\section{COLUMNS FORMAT}

\section{DESCRIPTION}

Option for number of replications to be drawn from each cell.

When NTRIES < 0: Then ABS (NTRIES) replications will be taken from each and every cell.

If NTRIES = 0: Not used.

If NTRIES > 0: The user inputs a number for each cell. This number is then multiplied by NTRIES to obtain the number of samples for each cell.

Cell definition option.

ISQARE = 0: User inputs coordinates for each cell in the state space.

ISQARE $=1:$ PRAISE-B internally sets up a regular grid of rectangular cells.

ISQARE $=2:$ If INCIAT $=1$

Number of transient types experienced by plant.

Initial crack size distributions.

KRKDIS $=1$ : Crack depth is log-normal. Aspect ratio is log-normal.

KRKDIS $=2:$ Crack depth is log-normal. Aspect ratio is exponential.

KRKDIS = 3: Crack depth is exponential. Aspect ratio is log-normal. 
CARD PROBLEM SPECIFICATION (Cont'd)

ID

LIB

READ Always

VARIABLE COLUMNS FORMAT

DESCRIPTION

KRKDIS $=4:$ Crack depth is exponential. Aspect ratio is exponential.

NEVAL $21-25 \quad 15 \quad$ Option for times during plant lifetime when the reliability is to be evaluated.

NEVAL < 0: Evaluation is performed for every ABS (NEVAL) year.

NEVAL > 0: Number of user supplied times that an evaluation is performed.

NINSPT

26-30

I5

NQUAKE $\quad 31-35$

I5

Number of user specif'ed in-service inspection times.

Seismic evaluation option.

NQUAKE $=0:$ No earthquakes are modeled.

NQUAKE $=1:$ Earthquakes at each evaluation time.

IDEBUG $\quad 36-40$

15

Debugging output option.

IDEBUG $=0$ : Normal output is printed.

IDEBUG = 1: Additional debugging output will be supplied.

$\begin{array}{lll}\text { KONPRP } & 41-45 \quad 15\end{array}$

Option for material constant (C) in the fatigue crack growth relationship.

KONPRP $=0: \mathrm{C}$ is log-normally distributed.

KONPRP $=1: C$ is constant; i.e., the crack growth relationship is deterministic. 
CARD PROBLEM SPECIFICATION (Cont'd)

ID

IB

READ Always

VARIABLE COLUMNS FORMAT

\section{DESCRIPTION}

NEQINT

$46-50$

I5

Number of seismic intensity classes to be simulated.

If $\mathrm{NQUAKE}=0$ s set $\mathrm{NEQINT}=0$.

PRAISE-B, as presently dimensioned, can handle up to 10 classes.

MCELLS $\quad 51.55$

KNSFLO

$56 \cdot 60$

I5

I5

Number of cells in the calculational grid.

If ISQARE $=1:$ The value of MCELLS is ignored.

Option for flow stress definition.

KNSFLO $=0$ : Flow stress is normally distributed.

KNSFLO $=1:$ Flow stress is constant.

NSK.IP

$61-65$

I5

Parameter to specify the number of evaluation times which are skipped in the printout of the indicator functions. Subroutine OUTS prints every NSKIP-th evaluation time.

NPSI

$66-70$

I5
Option for pre-service ultrasonic inspection.

NPSI $=0$ : No pre-service inspection.

NPSI $=1:$ A pre-service inspection is modeled. 
READ Always

VARIABLE COLUMNS FORMAT

ISCC

71.75

I5

ISIGRS

$76-80$

15

\section{DESCRIPTION}

Option for modeling stress corrosion sracking (SCC).

ISCC $=1$ : Stress corrosion cracking only.

ISCC $=0:$ Fatigue only (no SCC).

ISCC $=-1:$ Both SCC and fatigue.

[If INCIAT $* 0$, then ISCC should be either 1 or -1 .]

Option for modeling contribution of welding residual stresses.

ISIGRS $=0:$ Residual stresses are not modeled.

ISIGRS $=1$ : Contribution of residual stresses is modeled (coefficients to be entered by the user).

ISIGRS $=2:$ Contribution of residual stresses is modele،. Built-in residual stresses for large (20-30 inch) line used.

ISIGRS $=3:$ Contribution of residual stresses is modeled. Built-in residual stresses for intermediate $(10-20$ inch) line used.

ISIGRS $=4:$ Contribution of residual stresses is modeled. Built-in residual stresses for small ( $<10$ irich) line used.

ISIGRS $=5:$ Contribution of IHSI residual stresses is modeled. User to input stresses on the inside and outside surface. 
CARD PROBLEM SPECIFICATION (Cont'd)

READ Always

VARIABLE COLUMNS FORMAT

DESCRIPTION

ISIGRS $=6$ : Contribution of IHSI or MSIP residual stresses is modeled. User to input the mean and the standard deviation of stress at the ID. 
CARD IHSI and MSIP RESIDUAL STRESS DEFINITION

ID 1 C0

READ Only if ISIGRS $=5$ or 6 , on Card $1 \mathrm{~B}$

VARIABLE COLUMNS FORMAT

RSIN

$1-10$

$11-20$

$1-10$

E10.3

RSINM

RSINSD

$1-10$

E10.3

\section{DESCRIPTION}

Residual stress on the inside surface of a pipe (ksi). (For ISIGRS $=5$ )

Residual stress on the outside surface of a pipe (ksi). (For ISICRS = 5)

Mean of the IHSI or MSIP residual stress on the ID in ksi. (For ISIGRS =6)

Standard deviation of the IHSI or MSIP stress on the ID in ksi. (For ISIGRS $=6$ ) 
VARIABLE COLUMNS FORMAT

KKA

$1-5$

I5

LLA

6-10

I5

$\mathrm{KKB}$

$11-15$

LLB

$16-20$

I5

\section{DESCRIPTION}

The number of $(a / b)$ terms in the polynomial which define the contribution of residual stress to the "RMS-averaged" stress intensity factor in the depth direction.

The number of $(\mathrm{a} / \mathrm{h})$ terms in the polynomial which define the contribution of residual stress to the "RMS-averaged" stress intensity factor in the depth direction.

The number of $(a / b)$ terms in the polynomial which define the contribution on residual stress to the "RMS-averaged" stress intensity factor in the length direction.

The number of $(a / h)$ terms in the polynomial which define the contribution of residual stress to the "RMS-averaged" stress intensity factor in the length direction. 
CARD TIME PARAMETERS, NDE PARAMETERS

READ Always

ID $\quad 1 D$

VARIABLE COLUMNS FORMAT

$\begin{array}{lll}\text { THRIZN } & 1-10 \quad \text { E10.3 }\end{array}$

$\begin{array}{lll}\text { DTSCC } & 11-20 \quad \text { E10.3 }\end{array}$

ICTYPE

$21-25$

IPTYPE

$26-30$

I5

\section{DESCRIPTION}

Maximum plant lifetime for the simulation (years).

Time step to be used in calculating SCC growth (years). Used only if ISCC $=1$ on Card 1B.

Crack orientation flag.

$=0:$ Circumferential crack analysis

$=1$ : Longitudinal crack analysis (disabled in current PC-PRAISE).

Default sets of NDE parameters EPST, ASTAR and ANUU for various pipe types.

$=0$ : Thick-walled austenitic pipe

$=1$ : Thick-walled ferritic pipe

$=2$ : Thin-walled austenitic pipe

Default values are as follows:

\begin{tabular}{|c|l|l|l|}
\hline IPTYPE & EPST & ASTAR & ANUU \\
\hline 0 & 0. & $0.5^{*}$ THICK & 1.6 \\
\hline 1 & 0.005 & 0.25 & 3.0 \\
\hline 2 & 0.005 & 0.25 & 1.33 \\
\hline
\end{tabular}


CARD TIME PARAMETERS, NDE PARAMETERS (Cont'd)

READ Always

VARIABLE COLUMNS FORMAT DESCRIPTTON

$\begin{array}{llll}\text { EPST } & 31-40 & \text { E10.0 } & \text { User-specified value of " } \epsilon \text { " parameter; }\end{array}$

overrides default value. Leave blank to use default.

ASTAR $\quad 41-50 \quad$ E10.0 User-specified depth of crack with 50\% probability of detection (inches); overrides default value. Leave blank to use default.

TRANSD $\quad 51-60 \quad$ E10.0

Transducer diameter (inches); defoult $=1.0$ inch.

ANUU $\quad 61-70 \quad E 10.0 \quad$ User-specified value of " $v$ " parameter; overrides default value. Leave blank to use default. 
CARD TIME PARAMETERS

READ Always

\section{VARIABLE COLUMNS FORMAT}

THRIZN

$1-10$

E10.3

DTSCC

$11-20$

E10.3

\section{ID $1 D$}

\section{DESCRIPTION}

Maximum plant lifetime for the simulation.

Time step to be used in calculating SCC growth.

Used only if ISCC $=1$ or -1 on Card $1 \mathrm{~B}$. 
CARD PIPE DIMENSIONS

READ Always

VARIABLE COLUMNS FORMAT

THICK

$1-10$

E10.3

RIN

$11-20$

E10.3

ELOVRR

$21-30$

E10.3
ID

2A

\section{DESCRIPTION}

Wall thickness of the pipe (inches).

Inside radius of the pipe (inches).

$L / R$ ratio: Not required if $I F A I L C=0$. 
CARD FATIGUE CRACK GROWTH CHARACTERISTICS

ID $\quad 2 B$

READ Always

VARIABLE COLUMNS FORMAT

THRHLD

$1-10$

$11-20$

$21-30$

CONSMU

EMEXP

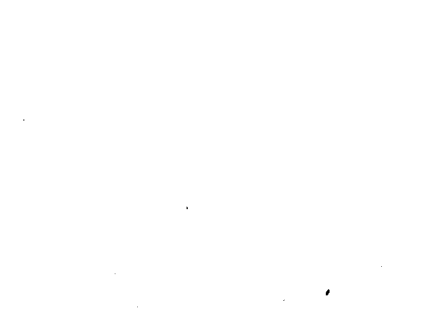

CONS90

$31-40$
E10.3

E10.3

E10.3

E10.3

\section{DESCRIPTION}

Threshold value in the crack growtia relationship $\left(\mathrm{ksi}^{-i \mathrm{in}^{1 / 2}}\right)$.

Exponent in the crack growth relationship.

Parameter for the constant in the crack growth relationship.

If KONPRP $=1:$ CONSMU is the constant.

If KONPRP $=0$ : CONSMU is the median of the log-normal distribution that describes the constant.

Parameter for the constant in the crack growth relationship.

If KONPRP $=1:$ CONS90 is ignored.

If KONPRP $=0:$ CONS90 is the 90th percentile of the log-normal distribution. 
CARD SCC VARIABLE

READ Always

VARIABLE COLUMNS FORMAT

OSTART $\quad 1-10$

OSTEDY $\quad 11-20$

TFSTDY $\quad 21-30$

DURATN

CONDUC
$31-40$

$41-50$
F10.5

F10.5

F10.5

F10.5

F10.5
ID $2 \mathrm{~B}-1$

\section{DESCRIPTION}

$\mathrm{O}_{2}$ at start-up (ppm).

$\mathrm{O}_{2}$ at steady state (ppm).

Steady-state temperature $\left({ }^{\circ} \mathrm{F}\right)$.

Duration of heat-up transient (in hours).

Coolant conductivity $(\mu \mathrm{S} / \mathrm{cm})$. 
CARD FLOW STRESS

READ Always

VARIARLE COLUMNS FORMAT

SFLOMU

$1-10$

E10.4

SFLOSD

$11-20$

$21-30$

XJIC

DJDAMT

$31-40$

$41-50$

$51-60$

E10.4

DEE

YOUNGS

$61-70$

E10.4

$\mathrm{XN}$

$7 i-80$

E10.4
ID $\quad 2 \mathrm{C}$

\section{DESCRIPTION}

The unean value of the flow stress (ksi).

Standard deviation of the flow stress (ksi). (Read if $\mathrm{KNSFLO}=0$. .)

$\mathrm{J}_{\mathrm{Ic}}$ (in-kips/in ${ }^{2}$ ) Required only if IFAILC $* 0$.

$\mathrm{d} J / \mathrm{da}$ in ksi Required only if IFAILC $\star 0$.

Yield strength in ksi. Required only if IFAILC $* 0$.

The constant $D$ in ksi in the power law $\epsilon=(\sigma / D)^{n}$ for hardening material.

Required only if IFAILC $\$ 0$.

Young's modulus in ksi. Required only if IFAILC $\$ 0$.

Exponent $\mathrm{n}$ in the power law $\epsilon=(\sigma / \mathrm{D})^{\mathrm{n}}$ for hardening material. Required only if IFAILC $\neq 0$. 
CARD INITIAL CRACK DEPTH DISTRIBUTION

READ Only if INCIAT *0

ID $\quad 3 A$

\section{VARIABLE COLUMNS FORMAT}

AMEDIN

$1 \cdot 10$

E10.3

ASIGMA

$11-20$

E10.3

ALAMDA

$1-10$

E10.3

\section{DESCRIPTION}

Median of the log-normal distribution on crack depth. (Read if KRKDIS $=1,2$ )

Shape factor ( $\approx$ standard deviation of logarithm of A) of the log-normal distribution on crack depth. (Read if $\mathrm{KRKDIS}=1,2$ )

Rate parameter $\left(\mathrm{IN}^{-1}\right)$ for exponential distribution on crack depth. (Read if $\mathrm{KRKDIS}=3,4$ ) 
CARD INITIAL CRACK ASPECT RATIO DISTRIBUTION
READ Only if INCIAT $=0$

VARIABLE COLUMNS FORMAT DESCRIPTION

BOAMED $\quad 1-10 \quad$ E10.3 Parameter analogous to the median in the truncated log-normal distribution on initial crack aspect ratio. (Read if $\mathrm{KRKDIS}=1,3$ )

BOASIG $\quad 11-20 \quad$ E10.3 Parameter analogous to the shape factor in the truncated log-normal distribution on initial crack aspect ratio. (Read if $\mathrm{KRKDIS}=1,3$ )

BOALDA $\quad 1-10 \quad$ E10.3 Rate parameter for shifted exponential distribution on initial crack aspect ratio. (Read if KRKDIS $=2,4$ ) 
CARD EARTHQUAKE EVALUATION TIMES

ID $\quad 4 A$

READ Only if NEVAL > 0

VARIABLE COLUMNS FORMAT DESCRIPTION

TEVAL $\quad 1-80 \quad 8 E 10.3 \quad$ Evaluation time (years). 
CARD IN-SERVICE INSPECTION TIMES

ID $4 B$

READ Only if NINSP'T $>0$

VARIABLE COLUMNS FORMAT

DESCRIPTION

TINSPT $\quad 1.80 \quad 8 \mathrm{E} 10.3 \quad$ In-service inspection time (years). 
CARD LEAK RATE AND DETECTION DEFINITIONS

ID $\quad 4 \mathrm{C}$

READ Always

VARIABLE COLUMNS FORMAT

FNDLEK

$1-10$

E10.3

ALKBIG

$11-20$

E10.3

\section{DESCRIPTION}

Threshold for leak rates which are detectable.

Threshold for discriminating between leaks and big leaks. 
CARD STRATIFIED SAMPLE SPACE

$\mathrm{READ}$ Only if ISQARE $=1$

VARIABLE COLUMNS FORMAT

$\mathrm{NAOH}$

$1-5$

I5

\section{DESCRIPTION}

Number of divisions of the $a / h$ coordinate in the sample space definition.

If the entire length of the $\mathrm{a} / \mathrm{h}$ coordinate is to be used, read in as NAOH. If the length of the $\mathrm{a} / \mathrm{h}$ coordinate is limited to the interval $A O H L O W \leq \mathrm{a} / \mathrm{h} \leq \mathrm{AOHUP}$, read in as $-\mathrm{NAOH}$. The a/h coordinate is limited to the region AOHLOW $\leq \mathrm{a} / \mathrm{h} \leq$ AOHUP.

NAOB $\quad 6-10 \quad 15$

AOHLOW $\quad 11-20 \quad$ E10.3

AOHUP

$21-30$

$\mathrm{E} 10.3$

Number of division of the $a / b$ coordinate in the sample space definition.

If the entire length of the $a / b$ coordinate is to be used, read in as NAOB. If the length of the $a / b$ coordinate is limited to the interval $A O B L F T \leq a / b \leq A O B R G T$, read in as $-N A O B$. The $a / b$ coordinate is limited to the region $\mathrm{AOBLFT} \leq \mathrm{a} / \mathrm{b} \leq$ AOBRGT.

Lower limit on the $\mathrm{a} / \mathrm{h}$ coordinate. (Ignored if $\mathrm{NAOH}<0$.)

Upper limit on the $\mathrm{a} / \mathrm{h}$ coordinate. (Ignored if $\mathrm{NAOH}<0$.)
AOBLFT $\quad 31-40 \quad$ E10.3

AOBRGT $\quad 41-50 \quad$ E10.3

Lower limit on the $a / b$ coordinate. (Ignored if $\mathrm{NAOB}<0$.)
Upper limit on the $a / b$ coordinate. (Ignored if $\mathrm{NAOB}<0$.) 
CARD STRATIFIED SAMPLE SPACE (Cont'd)

ID $\quad 5 \mathrm{~A}$

READ Only if ISQARE $=0$

VARIABLE COLUMNS FORMAT

$\operatorname{AOHSIZ(M,1)} \quad l-10 \quad \mathrm{E} 10.4$

$\operatorname{AOHSIZ(M,2)} \quad 11-20 \quad$ E10.4

AOBSIZ(M,1) $\quad 21-30 \quad$ E10.4

$\operatorname{AOBSIZ(M,2)} \quad 31-40 \quad$ E10.4

$\begin{array}{lll}\text { NUMTRY } & 41-50 \quad \mathrm{I} 10\end{array}$

\section{DESCRIPTION}

Lower boundary of the $\mathrm{a} / \mathrm{h}$ coordinate in the definition of the $\mathrm{m}$-th stratification cell.

Upper boundary of the $\mathrm{a} / \mathrm{h}$ coordinate in the definition of the m-th stratification cell.

Left boundary of the $a / b$ coordinate in the definition of the $m$-th stratification cell.

Right boundary of the $a / b$ coordinate in the definition of the $\mathrm{m}$-th stratification cell.

Number of replications to be taken from the m-th cell. 
CARD STRATIFIED SAMPLE SPACE (Cont'd)

ID $\quad 5 \mathrm{~A}$

READ Only if ISQARE $=1$ and NTRIES $>0$

\section{VARIABLE COLUMNS FORMAT DESCRIPTION}

NUMTRY(M) $\quad 1-50 \quad 5 \mathrm{I} 10 \quad$ Number of replications to be taken from the m-th cell. 
CARD STRESS VALUES

ID $6 \mathrm{~A}$

READ Always

VARIABLE COLUMNS FORMAT

SIGCLD $\quad 1-10 \quad$ E10.3

DESCRIPTION

Deadweight stress (ksi). This is the load controlled stress in the cold shutdown condition.

$\begin{array}{lll}\text { SGDWTE } \quad \text { 11-20 } \quad \text { 10.3 } & \begin{array}{l}\text { Deadweight and restraint of thermal } \\ \text { expansion components of stress in the hot } \\ \text { normal operating condition. }\end{array}\end{array}$

$\begin{array}{lll}\text { OPPRES } & 21-30 \quad \text { E10.3 }\end{array}$

Normal operating pressure of the system (ksi).

PRFPRS $\quad 31-40 \quad$ E10.3 Pressure in hydrostatic proof test (ksi).

If no proof test is to be modeled, set this value to any arbitrary negative number.

SIGVIB $\quad 41-50 \quad$ E10.3

Peak-to-peak amplitude of the high cycle vibratory stresses $(\mathrm{ksi})$.

If SIGVIB < 0: No vibratory stresses are modeled.

VBTHLD $\quad 51-60 \quad$ E10.3

Threshold value of the load ratio $\left(\mathrm{R}^{*}\right.$ in Section 3.9 of NUREG/CR-2301) which is used in the vibratory stress model. 
CARD SPECIFICATIONS FOR THE TABLES IN THE $\mathbf{g}_{\min }$

AND $g_{\max }$ FUNCTIONS

READ Only if KTYPES $>1$

VARIABLE COLUMINS FORMAT

NX

NY

6-10

$11-15$

$16-20$

IY
I5

I5

I5

I5

\section{DESCRIPTION}

Number of entries in the $a / b$ coordinate for the input of the $\mathrm{g}^{*}{ }_{\min }$ and $\mathrm{g}^{*}{ }_{\text {max }}$ functions.

Number of entries in the $a / h$ coordinate for the input of the $\mathrm{g}^{*}{ }_{\text {min }}$ and $\mathrm{g}^{*}{ }_{\text {max }}$ functions.

Number of entries in the $a / b$ coordinate for the internal tables on the $g_{\min }$ and $g_{\max }$.

Number of entries in the $a / h$ coordinate for the internal tables on $g_{\min }$ and $g_{\max }$. 
CARD A/H COORDINATES FOR TABULAR INPUT OF

ID $\quad 6 \mathrm{C}$ CONTRIBUTION FROM RADIAL GRADIENT THERMAL STRESSES TO STRESS INTENSITY FACTOR

READ Only if KTYPES > 1

VARIABLE COLUMNS FORMAT

\section{DESCRIPTION}

$\begin{array}{lll}\mathrm{AAOH}(\mathrm{I}) & 1-80 \quad 8 \mathrm{~F} 10.3\end{array}$

Values of the $a / h$ coordinate in the tabulated input for the contribution of radial gradient thermal stress to the stress intensity factor $(I=1, \ldots, N Y)$. 
CARD B/A COORDINATE FOR TABULAR INPUT OF

ID $\quad 6 \mathrm{D}$ CONTRIBUTION FROM RADIAL GRADIENT THERMAL STRESSES TO STRESS INTENSITY FACTORS

READ Only if KTYPES > 1

VARIABLE COLUMNS FORMAT

$\mathrm{ABOA}(\mathrm{I}) \quad 1.80$

$8 \mathrm{~F} 10.3$

\section{DESCRIPTION}

Values of the $b / a$ coordinate in the tabulated input for the contribution of radial gradient thermal stresses to the stress intensity problem $(I=1, \ldots, N Y)$. 
CARD FREQUENCY OF HEAT-UP/COOL-DOWN AND ID GE TRANSIENTS

READ Always

VARIABLE COLUMNS FORMAT DESCRIPTION

NCYBLK $\quad 1.5$

Number of cycles in the equivalent event.

$\operatorname{BLAMDA}(\mathrm{K}) \quad 6-10 \quad$ F5.2 $\quad$ Arrival time parameter for transients.

If $\operatorname{BLAMDA}(\mathrm{K})>0.0$ : Then $\mathrm{k}$-th transient arrives at uniformly spaced intervals of BLAMDA(K) years.

If BLAMDA $(\mathrm{K})<0.0$ : Then $\mathrm{k}$-th transient is treated as a Poisson's process with ABS $(\operatorname{BLAMDA}(\mathrm{K}))$ as the average number of arrivals per unit time.

If stress corrosion crack initiation is included, then BLAMDA(K) should always be greater than 0.0 (the transient arrival times uniformly spaced).

$\operatorname{TEMP}(\mathrm{K}) \quad 11-20 \quad \mathrm{~F} 10.5$

Temperature excursion $\left({ }^{\circ} \mathrm{F}\right)$ during the $\mathrm{k}$-th transient.

TITLE $(\mathrm{K}) \quad 21-80 \quad 6 \mathrm{~A} 10 \quad$ Description for the $\mathrm{k}$-th transient type. 
CARD TABULATED FUNCTIONS FOR $\mathrm{g}^{*}{ }_{\min }$ AND $\mathrm{g}^{*}{ }_{\text {max }}$

ID $\quad 6 \mathrm{~F}$

READ All transients except the heat-up/cool-down, l.e., $K>1$

\section{VARIABLE COLUMNS FORMAT DESCRIPTION}

This outer loop is on the b/a coordinate and is read in reverse order or $(I=N X$, $\mathrm{NX}-1, \ldots, 1)$.

$\begin{array}{llll}\operatorname{GDAMIN}(\mathrm{I}, \mathrm{J}, \mathrm{K}) & 1.72 & 9 \mathrm{~F} 8.5 & \mathrm{~g}^{*}{ }_{\mathrm{min, \textrm {a }}}(\mathrm{J}=1, \ldots, \mathrm{NY}) . \\ \operatorname{GDAMAX}(\mathrm{I}, \mathrm{J}, \mathrm{K}) & 1.72 & 9 \mathrm{~F} 8.5 & \mathrm{~g}^{*}{ }_{\text {max,a }}(\mathrm{J}=1, \ldots, \mathrm{NY}) . \\ \operatorname{GDAMIN}(\mathrm{I}, \mathrm{J}, \mathrm{K}) & 1-72 & 9 \mathrm{~F} 8.5 & \mathrm{~g}^{*}{ }_{\min , \mathrm{b}}(\mathrm{J}=1, \ldots, \mathrm{NY}) . \\ \operatorname{GDAMAX}(\mathrm{I}, \mathrm{J}, \mathrm{K}) & 1-72 & 9 \mathrm{~F} 8.5 & \mathrm{~g}^{*}{ }_{\text {max, }}(\mathrm{J}=1, \ldots, \mathrm{NY}) .\end{array}$


CARD COEFFICIENTS FOR THE POLYNOMIAL THAT DEFINES ID $\quad$ GG THE CONTRIBUTION OF WELDING RESIDUAL STRESSES

TO THE STRESS INTENSITY FACTOR IN THE DEP'TII

DIRECTION

READ Only if ISIGRS $=1$ on Card $1 \mathrm{~B}$

VARIABLE COLUMNS FORMAT

DESCRIPTION

$\mathrm{B}(\mathrm{L}, \mathrm{K})$

$1-80$

$8 \mathrm{E} 10.3$

$(b(1, k), 1=1, L L A)$.

A separate card is used for each value of $k$ $(\mathrm{k}=1, \ldots, \mathrm{KKA})$.

LLA corresponds to $\mathrm{L}$ in Equation 3-11; KKA corresponds to $\mathrm{K}$ in Equation 3-11 (NUREG/CR-2301). 
CARD COEFFICIENTS FOR THE POLYNOMIAL THAT

ID $\quad 6 \mathrm{HI}$

DEFINES THE CONTRIBUTION OF WELDING

RESIDUAL STRESSES TO THE STRESS

INTENSITY FAC'TOR IN THE LENGTH DIRECTION

READ Only if ISIGRS $=1$ on Card $1 \mathrm{~B}$

VARIABLE COLUMNS FORMAT

DESCRIPTION

$B(L, K)$

1.80

$8 \mathrm{E} 10.3$

$(b(1, k), 1=1, \ldots, L L B)$.

A separate card is used for each value of $k$ $(\mathrm{k}=1, \ldots, \mathrm{KKB})$.

LLB corresponds to L in Equation 3-11; KKA corresponds to $\mathrm{K}$ in Equation 3-11 (NUREG/CR-2301). 
CARD EARTHQUAKES PER MAGNITUDE CATEGORY

ID $\quad 7 \mathrm{~A}$

READ Only if NQUAKE $=1$ on Card $1 B$

VARIABLE COLUMNS FORMAT

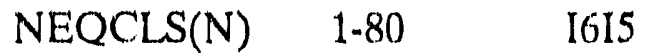

\section{DESCRIPTION}

Number of earthquakes in the n-th magnitude category. A maximum of ten earthquakes can be modeled in each category. 
CARD SEISMIC CRACK GROWTH PARAMETERS

ID

$7 B$

READ Only if NQUAKE $=1$ on Card $1 B$

\section{VARIABLE COLUMNS FORMAT DESCRIPTION}

The following card is repeated for each earthquake that is modeled. They are grouped by earthquake intensity category. $\mathrm{N}$ is the index on the intensity category, while LEQ is the index on earthquakes within an intensity category.

\begin{tabular}{|c|c|c|c|}
\hline NCYCEQ(N,LEQ) & $1-10$ & 110 & $\begin{array}{l}\text { Number of equivalent cycles use } \\
\text { represent the crack growth. }\end{array}$ \\
\hline $\operatorname{SIGEQ}(\mathbb{N}, L E Q)$ & $11-20$ & F10.3 & $\begin{array}{l}S^{4} \ldots \text { The fourth power of the } \\
\text { S-factor. }\end{array}$ \\
\hline SGEQMX(N,LEQ) & $21-30$ & F10.3 & The load-controlled stress (ksi). \\
\hline TITLE(N,LEQ) & 31.80 & $5 \mathrm{~A} 10$ & $\begin{array}{l}\text { Description for this particular } \\
\text { earthquake. }\end{array}$ \\
\hline
\end{tabular}



CARD INPUTS FOR MID-LIFE CHANGES IN

ID

OPERATING S'TRESSES, CHEMISTRY,

OR RESIDUAL STRESSES

REAI Only if IREMED > 0

VARIABLE COLUMNS FORMAT

RTIMES(I) $\quad 1-10 \quad$ E10.4

THICKS(I) $\quad 11-20 \quad$ Fi0.4

$\operatorname{OSTARS}(1) \quad 21-30 \quad$ E10.4

$\operatorname{OSTDYS}(I) \quad 31-40 \quad$ E10.4

CONDUS(I) $\quad 41-50$

SGCLDS(I) $\quad 51-60$

SDWTES(I) $\quad 61-70$

SGVIBS(I) $\quad 71-80$

$\operatorname{ISIGRX(I)~} \quad 1-10$

RSINMS(I) $\quad 11-20$

RSISDS(I) 21-30

E10.4

E10.4

\section{DESCRIPTION}

Time (in years) at which one or more of the following variables are changed.

Wall thickness of pipe (inches).

$\mathrm{O}_{2}$ at start-up (ppm).

$\mathrm{O}_{2}$ at steady state (ppm).

Coolant conductivity $(\mu \mathrm{S} / \mathrm{CM})$.

E10.4 Deadweight stress (ksi).

E10.4 Deadweight and restraint of thermal expansion components of stress in the hot normal operating condition (ksi).

E10.4 Peak-to-peak amplitude of the high cycle vibratory stresses $(\mathrm{ksi})$. If SIGVIB $<0$, no vibratory stresses are modeled.

IHSI or MSIP residual stress flag (6 or 7). A value of 7 indicates no change from the previous state.

Mean value of the stress at the ID in ksi (MSIP or IHSI stress). Not required if ISIGRX(I) is 7.

Standard deviation of the stress at the ID in ksi (MSIP or IHSI stress). Not required it ISIGRX(I) is 7. 

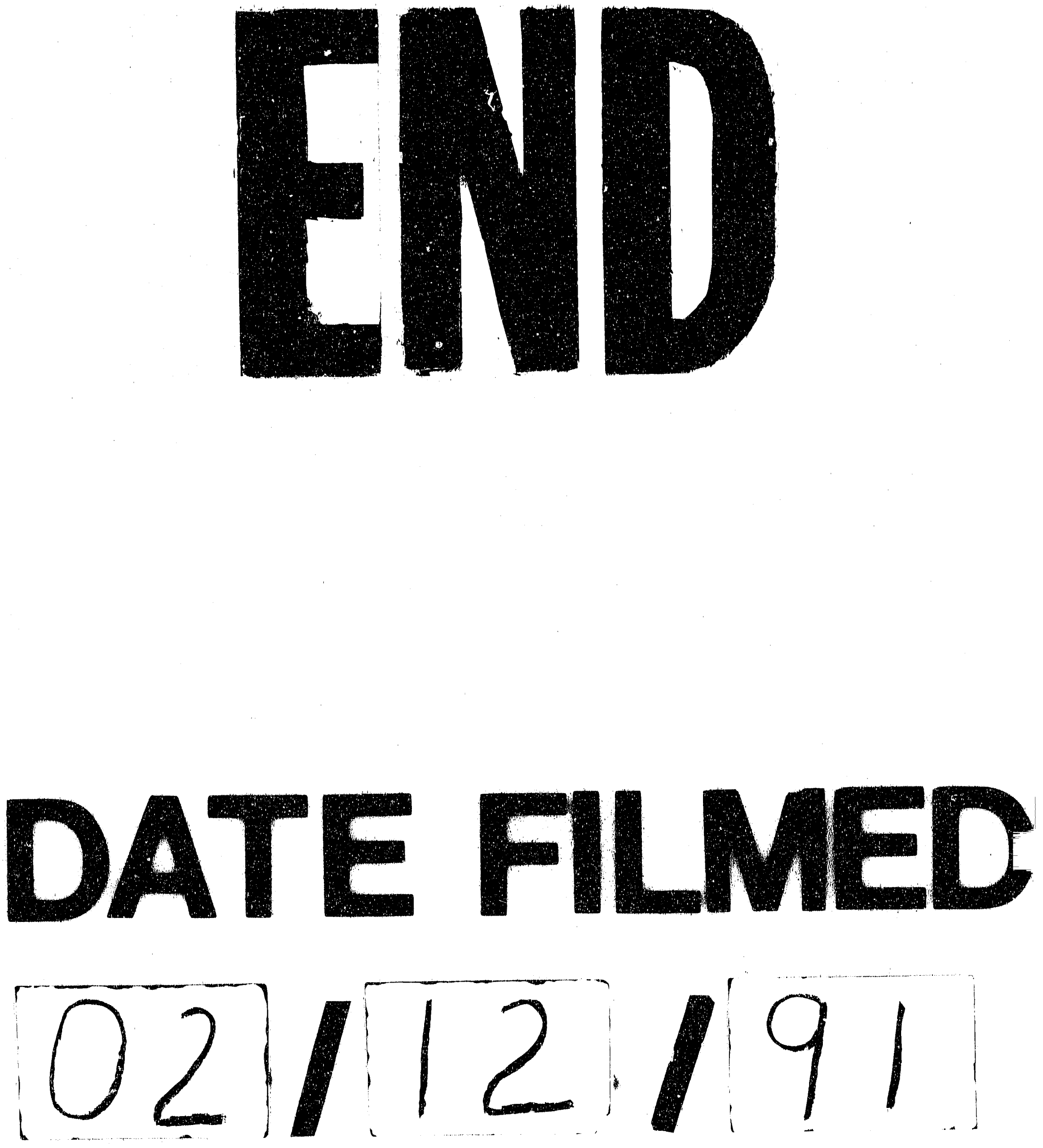


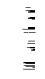

